\title{
العلامات اللغوية والمرجعية الثقافية في روايات الطيب صالح "ورقة بحثية في النقد الثقافي"
}

أ/ إسحق علي محمد

باحث في النقا الأدبي والثثافي

محاضرمتعاون بكلية أفريقيا الجامعية

د. محاسن الفحل

أستاذ مشارك بكلية اللغات

جامعة السودان للعلوم وإلتكنولوجيا

مـدمة

مما لا شك فيه، أن الأدب مرآة الثعوب، وخاصة الادب النثري منه، ولذلك كان اختيارنا لروايات

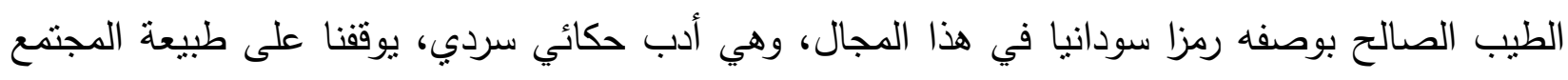

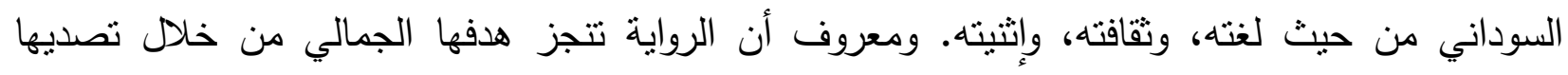
لمعضلات اجتماعية، وثقافية، ولغوية حفظتها الموروثات، والمعتقدات بواسطة كثفها للبنى، والأنساق الفاعلة فيها، وبذللك تتجز الرواية مهنتها في التغيير، والتحريض، والتطور، والتقدم. وهذا اساس النقد التقافي الذي ولئي

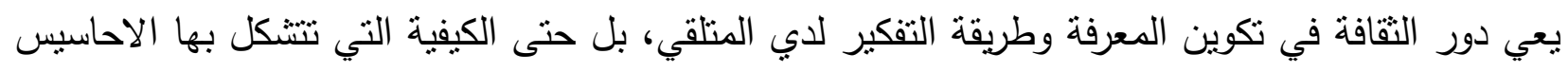

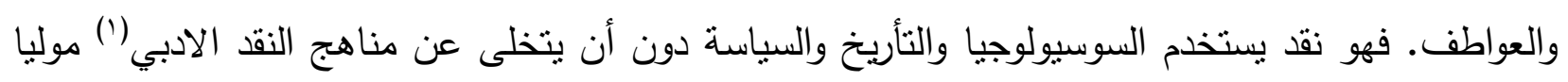
عناية بالنسق، والتأويل والمرجعية الثقافية، والمسكوت عنه، باتجاه خطاب عالمي انساني (؟). الأهداف: / / معرفة ماهية العلامة اللغوية وعلاقتها بالثقافة والهوية السودانية. ب/ معرفة المرجعية الثقافة

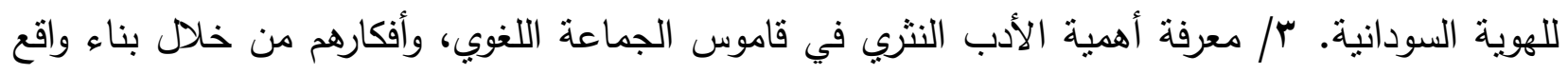
خيالي سردي، يعالج إثنكالات الواقع المعيش، ويبصر بمسنقبل مشرق، ويحرّض على التغيير • \& / الاسهام في درسات النقد الثقافي في المكتبة العربية. 


\section{مجئة كية اتربية مجامعة واسط}

المنهج: المنهج السيميائي الذي يهنم بالعلامات اللغوية أكثر المناهج ضرورة في هذه الورقة لأنه يدرس كل أنساق العلامات التي بفضلها يتحقق التواصل بين الناس(r)، وهذه التواصل هو صميم جدل اللغة والتقافة.

المصطلحات

اللغة: وفي هذه الورقة سوف أتعامل مع اللغة كونها إنسانية، وظيفتها الاتصال من خلال علامات دالة هي الحروف، والكلمات، والجمل، والسياق، والنّص؛ في بنية، ونظام نحوي، ودلالي، وصرفي؛ أنتجه الإنسان،

لبدلل على انتمائه للجماعة المعنية.

الثقافة: معظم التعريفات لكلمة ثقافة في العصر الحديث، وضعت نصب أعينها تعريف عالم الاجتماع ادوارد تايلور في كتابه (الثقافة البدائية) الذي يقول: "الثقافة هي ذلك الكل المعقّ الذي يتضمن المعارف والمعتقدات، والفنون، والآداب، والأعراف والقوانين. وغير ذللك من منجزات الإنسان كفرد أو كمجتمع.(؛) بعضهم زاد، والآخر شرح، وفصّل، ولكنه ارتكز على تايلور • وقد لخّص تيري ايجيلتون مفهوم الانثربولوجيين للتقافة بقوله: "التقافة هي طريقة حياة شعب يعيش معا في بقعة واحدة"(0) ويضيف:"ما من مشكل معرفي أثندّ دهاء وبراعة ليري في رسم خارطة لتعقيدات القلب (الوجدان) من التقافة الفنية، وهذا ما جعل الرواية الواقعية مصدرا للمعرفة الاجتماعية أند تفصيلا، وصميمية بما لا يقاس بأي علم اجتماع وضعي"(ج).

وأستطيع أن تعامل مع مفهوم اليونسكو للتقافة في هذه الدراسة، وكما ينظر اليها اليوم على أنها:

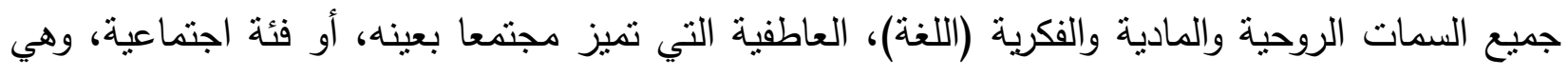

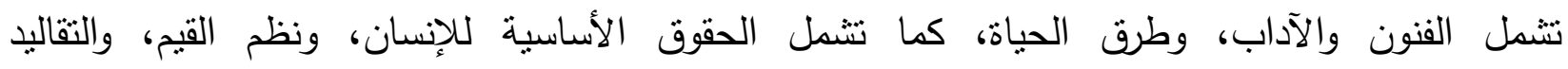

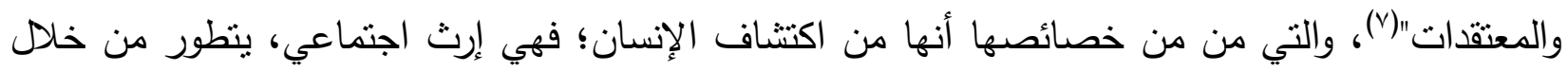
الفن، والفكر، والسلوك. وأنها قابلة للتعديل، والتعبير من جيل لآخر ، حسب الظروف الخاصة بكل مرحلة؛

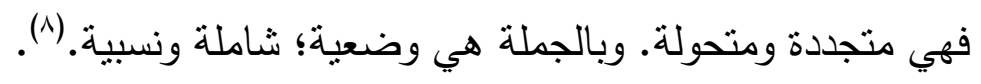

العلامة اللغوية: طبيعة اللغة أنها نظام مغلق . بنية ـ صارمة في قواعدها، وهي بذلك تحدد طريقة تعبيره، وحالما يدخل الفرد عالمها يتقيد بنظامها، وتعطيه هي صفة المجتمع الذي يتحدث بها. فنحن أمام مفردات 


\section{مجية كيّة |تربية مجامعة واسط}

هي علامات لها دلالات معجمية توافقية، تخص جماعة المتكلمين بهذه اللغة؛ تركب في جمل؛ هذه الجمل هي علامات أيضا تتركب في نص هو وحدة كتابية.

المرجعية الثقافية: ولكي يتواصل الفرد مع أفراد المجمع، فإن اللغة تحيله إلى خارج النص لاكتساب دلالات؛ هي المرجعية التي يركن إليها الآخرون لكي يفهوا كلامه ـ معناه ـ ، هذه المرجعية يحددها سياق اللغة، وهو المقام الذي يناسب تركيبه اللغوي، ليفيد دلالة محددة، يفسرها الآخرون من خلال مخزون ثقافي هو المرجعية.

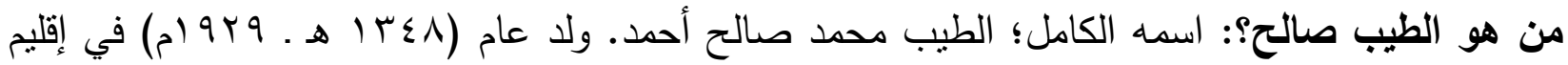
مروي شمال السودان بقرية كَرْكَكول بالقرب من قرية دبة الفقراء؛ وهي إحدى قرى قبيلة الركابية التي ينتسب

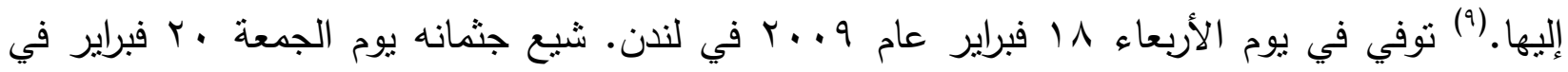

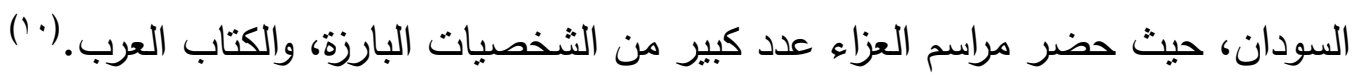

رواياته: كتب الطيب صالح العديد من الروايات التي ترجمت إلى أكثر من ثلاثثن لغة وهي: "نخلة على

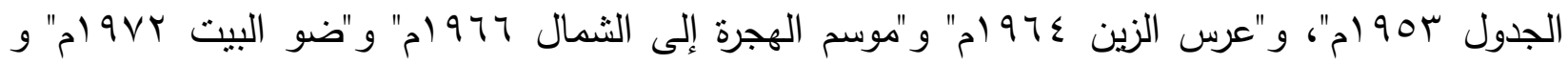

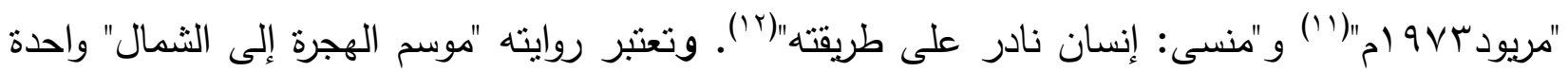

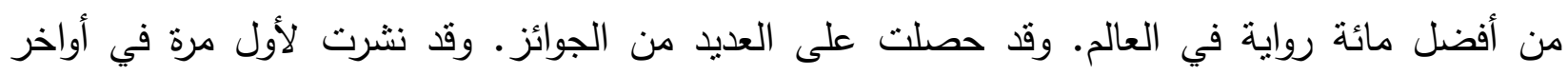

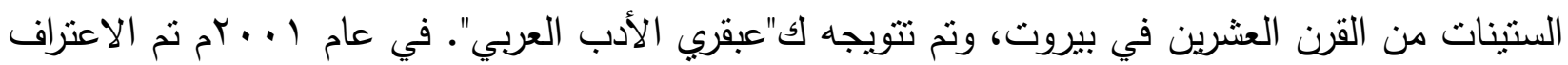
بكتابه من قبل الأكاديمية العربية في دمثق، على أنه صاحب "الرواية العربية الأفضل في القرن العشرين. في فبراير من العام |l لـrم تم الإعلان عن جائزة الطيب صالح العالمية للإبداع الكتابي، تقديرا للاور الكبير الذي قام به في الثقافة العربية(ז'). وطبعت أعماله في كتاب من منشورات مركز عبد الكريم

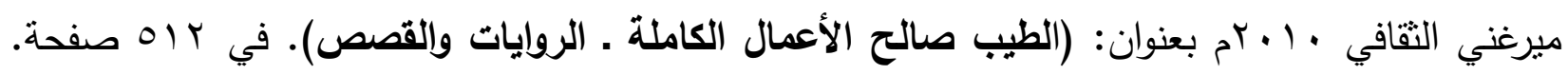
وهو الكتاب الذي سوف نعتمد عليه في هذه الورقة.

\section{العلامة اللغوية والمرجعية الثقافية للنص}




\section{مجئة كية اتربية مجامعة واسط}

"اللغة تقاليد وأنظمة(\{ ()؛ نقاليد اجتماعية بها تتحقق التتشئة الاجتماعية للفرد- المتكلم- وأنظمة من العلامات ـ الكلمات والجمل والنصوص ـ تثبير فيها العلامة إلى دال هو الصورة السمعية؛ هذا الدال يشير إلى الصورة الذهنية/ الدفهوم وهو المدلول. هذا على مستوى العلامة المفردة، لكن اللغة نظام من العلامات التي تدخل في علاقات أكثر تعقيدا؛ هو نظام النحو -الجملة- وتزداد درجة التغقيد فتتجاوز حدود الجملة إلى النص (10)؛ بوصفه وحدة لغوية محددة كتابيا تضم في العادة أكثر من جملة"(1").

هذا يعني أن اللغة تفرض علينا نظاما يجب أن نتبعه في ترتيب الكلمات وتتظيمها في الأقوال، لأنه لكل كلمة موضعا نظهر فيه، كما تحدد وظيفتها النحوية تبعا لهذا الموضع/الموقع. فإذا اختلف الموضع اختلفت الوظيفة النحوية. وإذا كان هذا التغيير في الموضع يغيّر في الوظيفة المرتبطة بالكلمة فإنه يؤثر كذلك في معناها، كما ترتبط العبارات فيما بينها مكونة عبارات أكثر تعقيدا ومنها جميعا يتكون النصل(v) .وعندما نرديد أن نتكلم فمن الضروري أن نختار بعض الكلمات الملائمة من ناحية القواعد والمعنى لكي نستطيع التعبير عما نريد أن ننقلة إلى الآخرين"(^)". وهكذا فإن إعطاء تعبير ما مدلولا، معناه صياغة القواعد العامة التي تتحكم في استعماله من أجل خلق مرجعية بالنسبة للأشخاص، أو الموضوعات المتعلقة به، ومعناه إقامة قواعد، وعادات، وأعراف تتحكم في الاستعمال الصحيح للتعبير(9) ـ مفردات، وجمل، ونص . حيث يتث تحديد مرجعية ينهض بها السياق وتحيل إلى كل ما له علاقة بالمؤشرات السياقية للنص والقضايا المادية التي تحيط

فاللغة، باعتبار أنها بنية لها قونينها الخاصة في طبيعتها ، النحو ـ واعتبار إحالتها إلى الاطار الخارجي للنص ـ المعنى ـ بهذا الاعبار تزمز إلى القيم المادية والمعنوية، ولعل ربط اللغة بالمحيط الخارجي بكل أنثكاله، ومكوناته يقي اللمارسة التأويلية، والتحليلية من تخطي هذه المرجعية التي تعكس الانتماء الثقافي، والمعرفي، والحضاري، لأن اللغة التي نتكل النص منها تحمل في طياتها آثار انتماء أصحابها إلى حضارة معينة، وثقافة محددة(·r). وهي التي تحدد علاقتنا بالوجود، وبالطريقة التي نفكر بها، فالكلمات علامات ورموز تتشكل بها وفيها رويتتا للعالم(r). 


\section{مجية كيلة |تربية مجامعة و اسط}

طبيعة اللغة أنها نظام مغلق ـ بنية ـ صارمة في قواعدها، وهي بذلك تحدد طريقة تعبيره، وحالما يدخل الفرد عالمها يتقيد بنظامها، وتعطيه هي صفة المجتمع الذي يتحدث بها. فنحن أمام مفردات هي علامات لها دلالات معجمية نوافقية، تخص جماعة المتكلمين بهذه اللغة؛ تركب في جمل؛ هذه الجمل هي علامات أيضا تتركب في نص هو وحدة كتابية. ولكي يتواصل الفرد مع أفراد المجتمع، فإن اللغة تحيله إلى خارج النص لاكتساب دلالات؛ هي المرجعية التي بركن إليها الآخرون لكي يفهوا كلامه ـ معناه ـ ، هذه المرجعية يحدها سياق اللغة، وهو المقام الذي يناسب تركيبه اللغوي، ليفيد دلالة محدة، يفسرها الآخرون من خلال مخزون ثقافي هو المرجعية.

بناء على هذا التأسيس لمفهوم طبيعة العلامة اللغوية، والمرجعية الثقافية، سوف أتتاول في هذه الورقة البحثية؛ العلامة اللغوية في روايات الطيب صالح، والمرجعية الثقافية لها، تحت عنوان: العلامات اللغوية والمرجعية الثقافية للنص، وسأتتاول فيه دلالة المفردات المعجية والسياقية والثقافية، وكذلك التركيب، وخاصة العناوين بوصفها المفاتيح الاجرائية التي تمدنا بمجموعة من المعاني التي تساعدنا في فلك رمز النص، ومن ثم الوقوف على طريقة استخدام الطيب صالح للغة بوصفها نظاما لايصال أفكاره إلى متلق يفك شفرة النص من خلال مرجعية ثقافية. وفق هيكل يقسم الورقة الى مطالب؛ المطلب الأول، وعنوانه: المعنى واقعة ثقافية، ويتناول مفهوم العلامة اللغوية وعلاقته بالمرجعية الثقافية. أما المطلب الثاني فيتناول المفردات والتركيب من خلال عناوين هي: العنوان، والمفردات التراكيب. التي هي الجمل. ثم خاتمة ونتائج

وتوصيات.

المطلب الأول: "المعنى واقعة ثقافية"(r)

كل مجتمع يخلق شيفراته الخاصة التي بستمدها الأفراد المنتمون إليه للتواصل فيما بينهم، وهي التي تسمح لهم بتبادل الدلالات واستهلاكها، بينما يتواصلون فيما بينهم، وعالمهم الخارجي. هذه الثيفرة هي أمارة أوسمة، أو هي شيء مدرك يمكن أن نستخلص منه توقعات، واستتناجات، وإنشارات خاصة بشيء آخر غائب، ومرتبط به(rr). هذه الثيفرة هي العلامة، وهي الوسيط بين الإنسان، وعالمه الخارجي، ولكنها لا تحيل 


\section{مجية كيّة |تربية مجامعة واسط}

إلى الواقع الموضعي مباشرة، وإنما تحيل الى عالم الصور الذهنية، والمفاهيم، والمدلولات. فهي دال رمزي، وأداة من خلالها "تأنسن الإنسان وانفلت من ربقة الطبيعة ليلج عالم النقافة الرحب الذي سيهبه طاقات تعبيرية هائلة"(؟)، من ذلك أية ايماءات، وأفعال تحيل إلى طريقة في الوجود، والفعل، والاحساس؛ مثل التعابير التي تعطى كعلامات للفرح، وكذلك كل حركة إرادية نعبّر من خلالها عن شيء، أو نخبر عنه. وكذلك كل كيان تصويري يمثل حدثا، أو قيمة من خلال خصائصه الثكلية؛ مثل الصليب، والمنجل، وجمجمة ميت...

وأما لسانيا؛ فالعلامة أداة يتم من خلالها تمنل مفهوم، أو موضوع خلال صورة سمعية ـ كلمة مثلا،

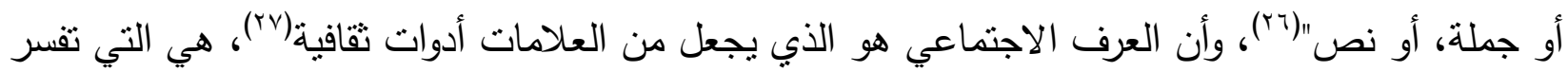
بها الجماعة نصوصها اللغوية"، فلا يمكن أن أفه كلمة إذا كنت أجهل اللغة التي تتنمي إليها هذه الكلمة...

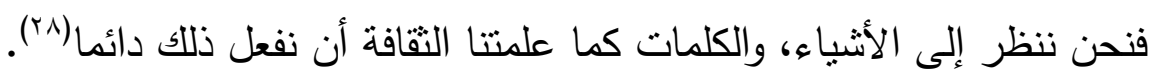

"والنص في تعريفه المعاصر ؛ هو سلسة من العلامات المنتظمة في نسق من العلاقات، تتتج معنى كلياً يحمل رسالة"(19+)، فإذا كان هذا النص رواية، فهو بالضرورة خطاب سردي، وهو بالتالي مجموعة من هن هئ العلامات اللغوية؛ (الحروف، والكلمات، والجمل، والصور البلاغية)، وهي محل التواصل ـ رسالة. مع المتلقي ـ المجتمع ـ الذي يستدعي مخزونه الثقافي للحضور في عملية التواصل هذه. فالعلامة دال يؤشر إلى صورة ذهنية/مفهوم، تتم ترجمته عبر وقائع، هي الكلمات، والجمل، والصور البلاغية إلى دلالة، تجد معناها في المخزون التقافي/المرجعية للفرد، ومن ثم تتتج معنى جديدا هو علامة/دال؛ وهكذا يستمر جدل اللغة والثقافة في تشكليل هوية الجماعات.

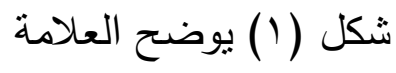

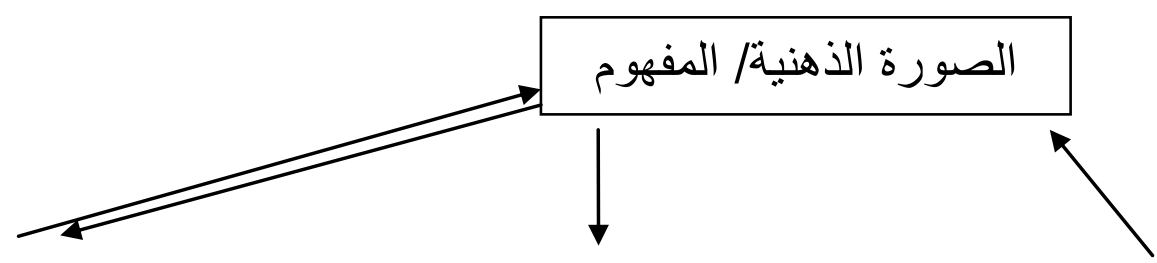

ايلول \& 1. r 


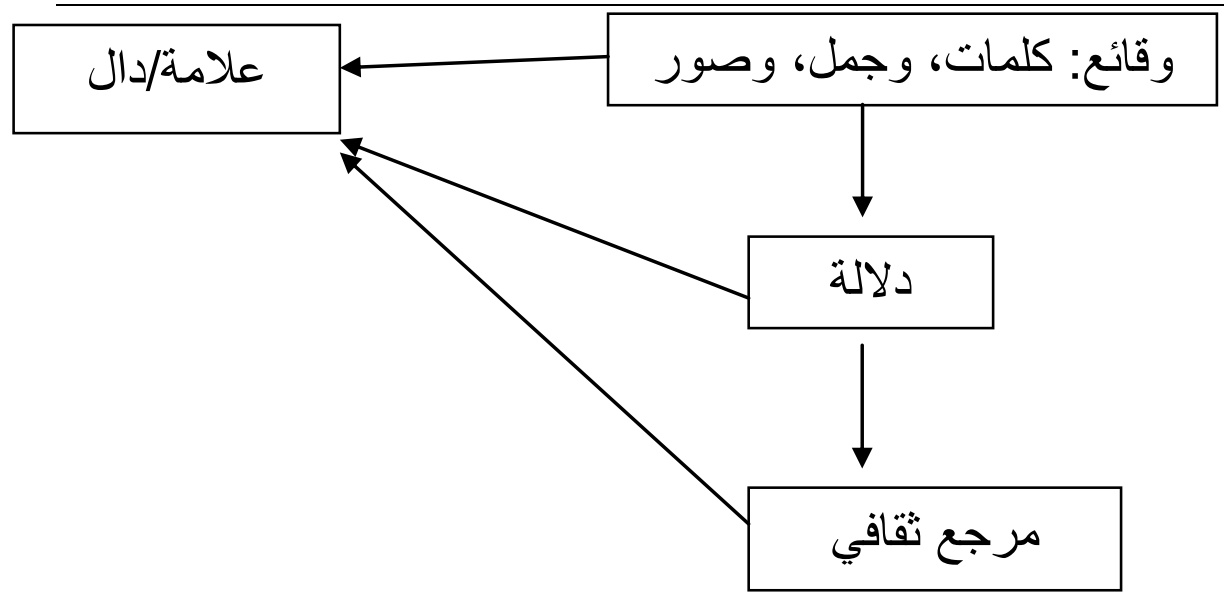

دال

المطلب الثاني: المفردات والتركيب:

يمكن النظر إلى اللغة من زاوية أنها توجيه مقعّد/تركيب مفيد، يقدّم المعنى بوصفه نتاجا لتأثير الفعل اللغوي؛ تأثنر معلوماتي، وتواصلي. في مواقف محددة تخضع لفعل الربط النحوي لمفاهيم/مضامين المفردات، في نصوص لغوية. ويمكن النظر إلى المعنى . في هذه الحالة. أنه نتيجة معلوماتية، وتواصلية للاستعمال المنظّم/المقعّد، لوسائل لغوية تستقيد من إمكانات السياق، والمقام، ليتحقق قصد الكاتب من خلال الأرصدة المضمونية التي تقدمها اللغة من خلال التركيب(· (r).

وعليه فإنه من الصعب أن يدرس النركيب بعيداً عن دلالته، ويفرض السياق؛ مجرى الكلام، وتسلسله، واتصال بعضه ببعض على تلك الدراسات، وكذللك المقام بوصفه الحالة التي يقال/يكتب فيها الكلام: حزن، أو فرح... إلخ. ذللك لأن التركيب لا ينعزل عن السياق بنوعيه؛ اللغوي/المعلوماتي، الذي يعتمد على النص، وغير اللغوي/التواصلي، الذي يعتمد على ما حول النص؛ من ظروف خارجية تفرض نفسها عليه (r).

وعندما نتناول التركيب، فإننا ندرس المفردات والجمل في روايات الطيب صالح لنقف على: كيف وظّف الكاتب إمكانات اللغة في أعماله الروائية ليوصل رسالته وليتواصل مع المنلقي من خلال المفردات 


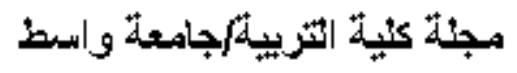

والتركيب والصفات، استتادا إلى مرجعية ثقافية مشتركة، لكي نبرز أثز الكاتب في هذه الثقافة بوصفها علامة

( ) (العنوان: (n)

"عنوان الرواية هو المفتاح الإجرائي الذي يمدّنا بمجموعة من المعاني، التي تساعدنا في فلك رموز

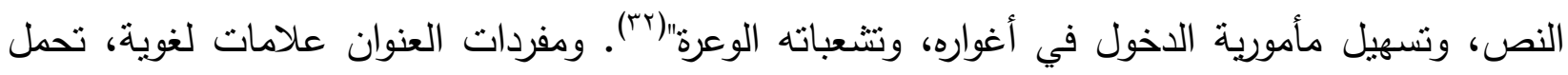
دلالات معينة على مستوى المعجم، المعج، والاصطلاح، والثقافة، والتأويل. وقد جاءت عناوين روايات الطيب صالح كالآتي (rॅ): (موسم الهجرة إلى الثمال - عرس الزين . ضو البيت (بندر شاه) ـ مريود (بندر شاه)، وعنوانان داخليان؛ هما سعيد عشا البايتات القوى، والطاهر ودالرواسي . منسي "إنسان نادر على طريقته"). فإذا كان "العنوان هو عنبة النص، وبدايته، وإنشارته الأولى، وهو العلامة التي تطبع النص،

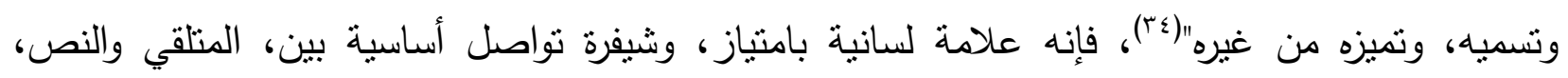
والكاتب، ومن ثم يحتاج المتلقي لفهم هذه العلامة من خلال مرجعية ثقافية؛ هي شرط التواصل، وإنتاج المعنى من خلا الوظائف التي يعطيها العنوان · بحسب جيرار جنيت، وهي التعبينية، والوصفية، والتضمينية، والإغرائية (ro).

• موسم الهرة إلى الثمال: يتكون العنوان من أربع كلمات؛ (ثلاث مفردات، وحرف)، ولكل مفردة دلالتها المعجمية، ثم بعد ذلك دلالة التركيب ككل، وهي الأساس في دلالة العنوان، ثلاث كلمات كلها أسماء؛ نكرة ومعرفتان، والاسم يدل على الثبات والتجريد.والجملة خبرها محذوف على تقدير الإشارة إليه: هذا موسم الهجرة إلى الثمال. بنية العنوان رباعية، وهي تمانل الاتجاهات الأربعة، ولكنها خصصت اتجاه الثمال، وكل كلمة في العنوان تحمل نقل موضعها، ودلالتها، وبالتالي هي علامات تؤشر دلاليا إلى معان ثقافية.

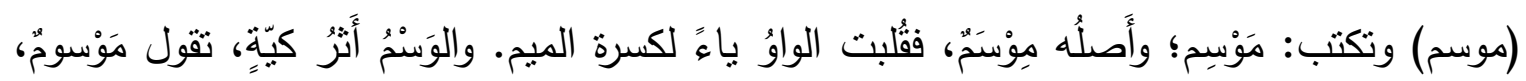

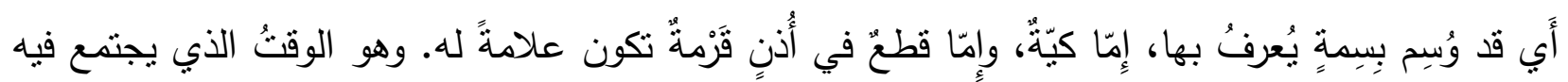

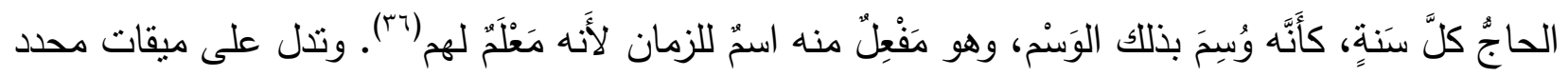




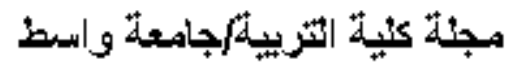

يتم فيه فعل مقترن ثقافيا بما هو مفرح متل الجمع للحج في دلالة دينية إسلامية، أو للحصاد، أو لمناسبة دينية كالأعياد (يوم الوقفة) آخر ايام في رمضان، واليوم التاسع من ذي الحجة. وارتبطت أيضا بهجرة الطيور في زمن معين من منطقة إلى أخرى. وبالجملة ترتبط المفردة موسم دلاليا بكل ما هو مفرح، ويكون في زمن معين يتكرر كل فترة. فنقول: مواسم الأفراح، وهي أيام الزواج بعد فترة الحصاد في الزراعة المطرية. وموسم تكتسب دلالتها من المضاف إليه، فهي نكرة غالبا تضاف إلى معرفة لتدل على زمن المضاف إليه، وتكون علامة له. موسم الهجرة، أي علامة الهجرة.

(الهجرة): جاء في لسان العرب(؟Y): الهِجْرَةُ من هجر وهي: الخروج من أَرض إِلى أَرض. وفيها دلالة

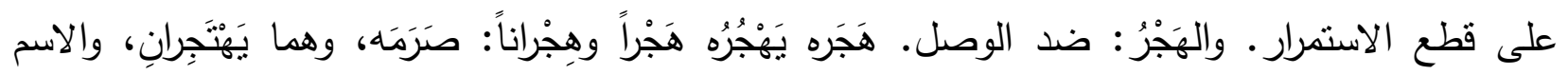
الهِجْرَةُ. وهَجَرْتُ الثُبه هَجْرَاً إِذا تركته وأَغفلته. و وتدل على معنى قطع الاستمرار والانتقال في حركة، وترتبط ثقافيا بمعنى الانتقال من بلاد الى أخرى، وهي علامة على أن البلد الأول لم يطب المقام فيه، وتتعدد الأسباب، في علامة هي موقف من استمرار البقاء/الحياة في هذا المكان، مما يدفع إلى الانتقال إلى غيره. وفي الذاكرة هجرة النبي (صلى الله عليه وسلم) ،وهجرة الطيور ... إلخ. " ولا تصبر الوحدة المعجية أداة موظفة للتواصل الاجتماعي إلا في سياق"(N").

(إلى): حرف جر يؤشر كعلامة إلى الاتجاه، ولا يحمل معنى في ذاته، بل يكتسب معناه من التركيب، ويجر الاسم بعده. ولا يمكن تجاهله في التركيب، في دلالة إلى سلطة اللغة ،وفرضها نظامها، وبنيتها. فهو رابط مهم في تأدية المعنى.

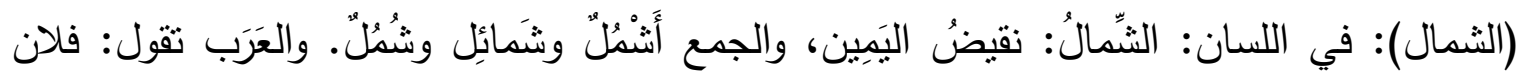

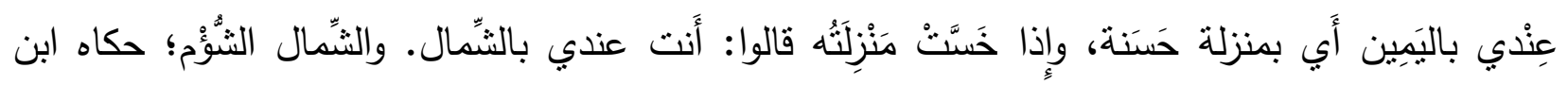

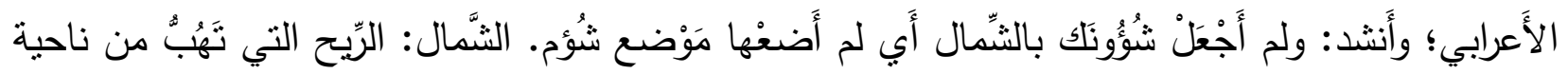
القُطْب. المعنى يتردد بين فتح الثنين وكسرها. وهو علامة تدل على اتجاه عكس الجنوب جغرافيا، وعكس اليمين نقافيا، وتؤشر إلى الأعلى في رسم الخرائط. والعلو مطلب ثقافي، لأنه يحمل معاني الأفضل، 
والأحسن، والخير كله. وتؤشر أيضا إلى معنى المثال؛ الأعلى، والأنموذج، وفيه دلالة على تقييم للجنوب مع حضور معنى الضد دائما (شمال/يمين)، في دلالة السياسة.

كل هذا التشظي في الدلالة فرضته هذه المفردات، بوصفها علامات تدل على مرجع ثقافي يولد مفهوما/دلالة، ربما لم يقصدها الكاتب، ولكنها تعطي المتلقي مشروعية انتمائه إلى اللغة. فإذا وصلنا إلى العنوان بوصفه تركيبا/علامة؛ فإنه يمنحنا فرصة ضيقة، تحدد خيارات المعنى. كأن الكاتب ييخل علينا بمتعة التوهان في إدراك المعنى. فهو يحدد موسم بالوقت، ناركا الصفة للمنلقي (أحسن/أسوأ)، وهي هجرة بمعنى ترك المكان إلى آخر، تاركا صفة (أحسن/أسوأ)، هجرة إلى مكان /اتجاه محدد؛ هو الثمال الأعلى/النموذج/اليسار ضد اليمين.

لعبة ذكية يلعبها معنا الكاتب، فكأنه يعطينا طرفا من حبل المعنى، ويمسك بالآخر في تساو واعتراف بقدرة المتلقي على إنتاج النص، مرتهنا إلى مرجعية ثقافية؛ هي المؤمن للمعنى في علامات العنوان، ليحل القارئ نفسه جدل التناقض في (الصفة) التي يعطيها للعلامة، بناء على تواصله مع النص/الرواية؛

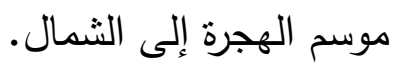

• عرس الزين: عنوان مكون من كلمنين فقط (نكرة، ومعرفة؛ مضاف ومضاف إليه) في صيغة مبندأ محذوف . الخبر المقدر بالظرف؛ زمان/اليوم/ومكان/هنا. أو في صيغة خبر محذوف المبتدأ المقدر بالإشارة إليه/هذا عرس الزين. (عرس): جاء في اللسان: والعُرْسُ والعُرُس: مِهْنَةُ الإملاكِ والبنِاء، وقيل: طعامة خاصة.

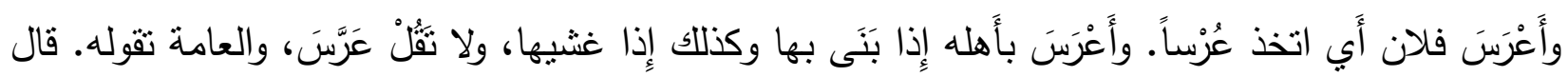
الأَّهري: العُرُس اسم من إِعْراسِ الرجل بأَهله إِذا بَنى عليها ودخل بها، وكل واحد من الزوجين عَرُوس؛ يقال للرجل: عَرُوس وعُرُوس وللمرأَة كذلك، ثم تسمى الوليمة عُرْساً.

فالمفردة علامة تؤشر إلى معنى النكاح/الزواج في الثقافة العربية، وترتبط بكل ما هوو مفرح ومبهج، وهي علامة على تجمع كبير للناس؛ باعتبار الإثهار في الزواج ـ ثقافيا ـ وفيه معاني الوليمة، والأكل، والغناء، والرقص في ثياب جميلة منتقاة، وحسان يظهرن مفاتتهن للعرض الخجول، ربما بحثا عن شريك 


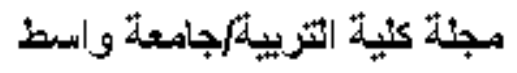

حياة. ويظهر معنى العنوسة مندسا في ايحاءات الخوف، وتتداعى قيم الكرم، والجمال، متضمنة معاني الضد؛ البخل، والقبح... إلخ.

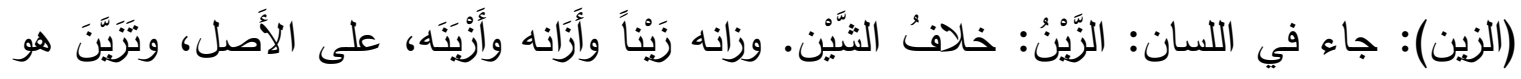

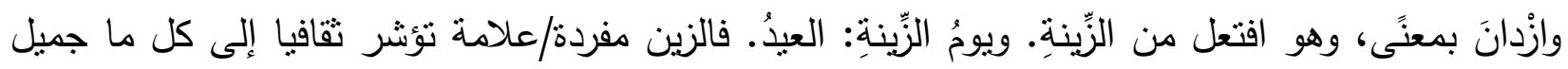
ماديا في الملابس والثكل الخارجي عموما/المظهر • ومعنويا في القيم السمحة التي قررها المجتمع وقبلها. نقول: هذا الثكل زين، وهذا الفعل زين. وتضفي ألف ولام التعريف (الزين) مع التضعيف في حرف الزاي معنى الاصرار على هذه الزينة، وهذا الجمال، كأنها ألف ولام العهد، بين الكاتب والمتلقي. مع أنه في العمل الروائي ـ شكلا ـ ليس زينا.

(عرس الزين) تركيب/علامة تدل ثقافيا إلى حفل زواج شخص اسمه الزين، وهي فرصة لجمع من الناس يتواصلون ثقافيا مع الحدث الذي يحمل معنى الفعل، على الرغم من أن بنية العنوان خالية منه، وتكتسب دلالة الاسم معنى الثبات، حيث لا شك في أنه عرس الزين؛ هذا الثخص الذب هو اسم على مسمى • من حيث المعنى . خاص بالزواج في الثقافة السودانية (العديل والزين)، وطقوس الحناء، فهو (عديل) لا عوج فيه، وهي صفة جميلة، وهو (زين) في كامل هندامه، وزيّه الباهي (عريس)، حيث ملتقى الأعين، وحلم العذارى، وخفقان قلوب العانسات.

مرة أخرى يسمي الكاتب عملا روائيا باسمين، لا فعل في العنوان من حيث البنية؛ (نكرة مضافة الى معرفة). لكنه في عنوانه عرس الزين؛ يترك المتلقي في حالة من التتويق لرؤية هذا (العريس الزين). والمفردة/المعرفة/الزين هي بؤرة حركة الكاتب في تعامله مع المنلقي، مستقيدا من إمكانات اللغة (التعريف والتضعيف)، ليقود مخيلة المتلقي هذه المرة بمهارة ويوجهها إلى الجزء الثاني من العنوان، وبكل وضوح وكأنه بينه وبين المتلقي عهد.

• بندر شاه: عنوان لعملين روائيين هما (ضو البيت، ومريود)، مكوّن من مقطعين أعجميين؛ يعطيان إمكان المضاف والمضاف إليه بالدرجة نفسها التي تدل على اسم مركب واحد، مثل (بعلبك). الأول بندر : جاء في ايلول \& 1. r 


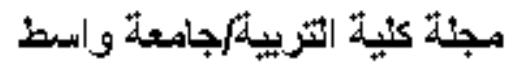

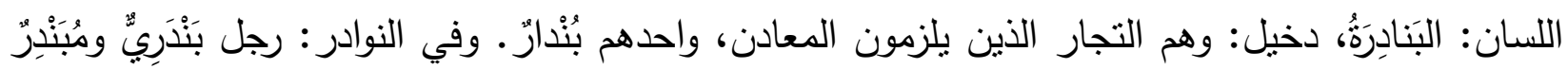
ومُنَبنْدِر ، وهو الكثير المال. واللفظ قريب من اللغة الفارسية تحصره العلامة (شاه) التي تؤشر إلى شاه ايران. وبندر علامة ثقافية تدل على المدنية، والحضر وهو المعنى الذي تدور حوله الرواية: "قالت مريم لمحيميد" نسكن البندر • سامع؟ البندر . الموية بالأنابيب والنور بالكهرباء، والسفر سكة حديد. فاهم؟ اتمبيلات وتطورات، اسبتاليات ومدارس، وحاجات وحاجات. البندر . فاهم؟" مريود/ ج9ז، والثاني: شاه: جاء في اللسان: والثاهُ...

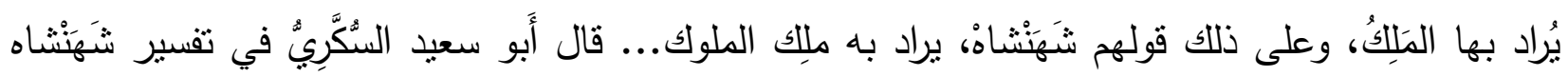

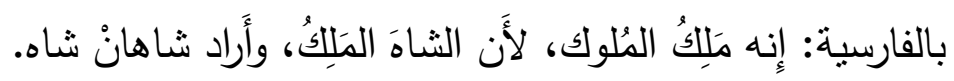

والتزكيب علامة تذل على لغة الجن، ويتداعى لفظ ( شمهروش) في عالم طقوس الثعوذة، والسحر ، وهي علامة تؤشر إلى الغيب والاعتراف بقدرة أعلى من قدرة الإنسان؛ عالم الجن مثلا. وهي علامة تدل على عالم الرواية الخيالي المليء بالعجائبية، وقصص الجن، وهو علامة النص الأولى في رأيي. وكأن الكاتب أراد أن يدلنا إلى عالم الرواية، بمفتاح هو عنوانها، لندخل عالم الغرائب، والعجائب، والخيال؛ (بندر شاه)، مع الاصرار على التتخيم لأن لله علاقة مهمة في تهيئة المتلقي لاخول ذلك العالم. "ففي (بندر شاه)؛ هذا المكان خلطتُ بين الأسطورة، والحلم، والواقع ،والتاريخ، فأريد أن أفهم لماذا هذا المكان؟ وما خصائصه، وأنا أنقصى لهى أيضا في قضية العلاقة بالسلطة، لأن بندر شاه ... بندر؛ المدينة وإشكالية الحلم، والمشكلة بالنسبة لنا هي

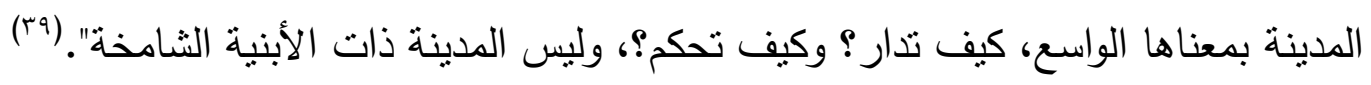
• ضو البيت: (ضو): مفردة عامية حذفت همزة الفصيح (ضوء)، وهي نكرة مضافة إلى معرفة، هي كلمة البيت، فاكتسبت معنى مفتوحا يصنفها علامة لسانية تحمل دلالة ثنائية ثقافيا. جاء في اللسان: الضَّوءُ

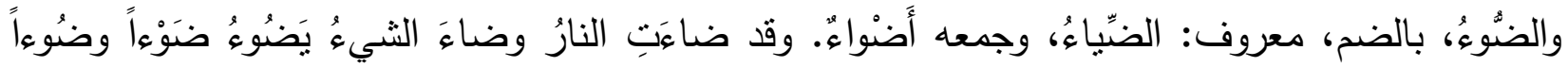
وأَضاءَ يُضِيهُ. فهي تذل على الضوء، وهو مفهوم يؤشر إلى الوضوح، عكس الظلام/الغموض، وتدل على الجمال، وتدل على الفرج، وفسحة الأمل. اكل 


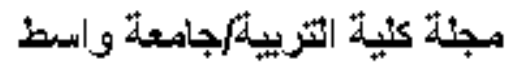

فإذا فهنا دلالتها العامية السودانية تصبح علامة تثير إلى الفعل أضاء، ومن ثم يكون الفاعل محذوفا، تقديره هو ، والفرق بين الاسم (ضوء)، والفعل ( ضوَّ) العامي يظهر في التتغيم الذي يظهره فتح الواو بعد تضعيفها في الفعل، وتسهيل نطقها في الاسم. ثمة دلالنان إذن تمدّنا بهما العلامة (ضو) فمن جهة هي اسم يدل على الإضاءة، وهي اسم له دلالته في الوعي التقافي السوداني، والعربي، ولكنه يبطن عكس ذللك؛ العتمة، والظلام. ومن جهة أخرى هي فعل ماض، فاعله محذوف وجوبا لأنه معروف، والدلالة موجبة عكسها

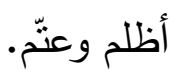

(البيت): جاء في اللسان: البَيْتُ من الثَََّرَ : ما زاد على طريقةٍ واحدة، يقَعَع على الصغير والكبير ...

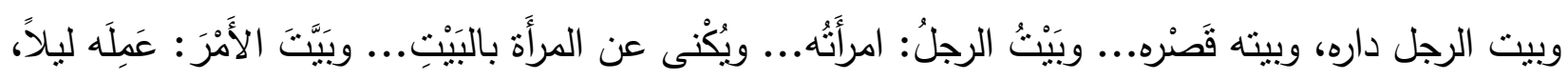
أَوْ دَبَّره ليلاً. البيت إذن اسم مكان، هو المسكن والمأوى، وهي مفردة تمنل علامة تدل على معنى الاتصاق بالناس، وتدل على محل الثقة، والأمان، وتدل أيضا على الراحة، والخصوصبة، والحباة المطلقة، والحماية."يشكل البيت مجموعة من الصور التي تعطي للإنسان براهين، أو أوهام التوازن، ونحن نعيد تخيل حقيقتها باستمرار .. ولتمييز هذه الصور نضفي روح البيت"(•؛). بندئ.

وأما التركيب (ضو البيت)، فهو علامة تتأرجح دلالتها بين الاسمية، والفعلية للعلامة (ضو)، مضافة الى مفردة البيت، أو مسندة إلى فاعل محذوف نصب مفعولا به (البيت). ودلالة التركيب/العلامة تؤشر إلى محذوف مبتدأ موصوف بأنه ضو البيت/خبر ، وهو في هذه الحالة اسم يحمل معنى ثقافيا دلالته أنه يشيع كل ما هو جميل، وناصع في البيت، حيث آخرون ينعمون بهذا الضوء، "قال عمي محمود: ضو البيت اسم مبارك. ولعل الرجل حل عندنا على هذه الحالة بالخير والبركة"ضو/ بrس، وهو علامة هذا البيت، ومركز حركته، وفعله، فهو عينه التي يرى بها، وهي جملة اسمية تفيد الثبات في هذه الصفة.

وتؤشر من جهة أخرى إلى فاعل محذوف، قام بفعل الإضاءة للبيت/المفعول به، وفي الفعل قيمة الحركة/الحدث المقرونة بالزمن، ويفهم أن البيت كان قبل ذلك مظلما فأنى الفاعل المعروف فأضاء البيت، والمعنى ثقافيا أنه حامل السعد والفأل. 


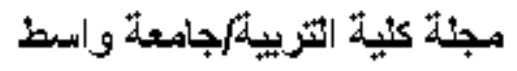

كأن الكاتب أراد أن يتأرجح المتلقي بين معنى الاسمية، ومعنى الفعلية في تركيب هذا العنوان، ليكون على علامة على قلق المعنى، وخبرة الكاتب، وتمرسه باللغة، فهو يخبرنا بهذه اللغة بوجوده، ليدخلنا إلى عالم الرواية، حيث نكابد متعة الكثف؛ (ضوء هو أم أضاء هو). وبين العلامنين سر إبداع الكاتب، ليقرر أن للسياق نأثير كبير في منح مدلول ما للعلامة عندما تكون هذه الأخبرة مرتبطة بدلالات متعددة( (\&). • مريود: عنوان مكون من كلمة واحدة على زنة مفعول، وهي وصف لمحذوف مبتدأ ، أو اسم إثشارة؛ (هو أو هذا). مشتقة من المصدر الفصيح رود، والزّرد: الطلب؛ فهو مروود/مطلوب، والموضع مُراد. وجاء

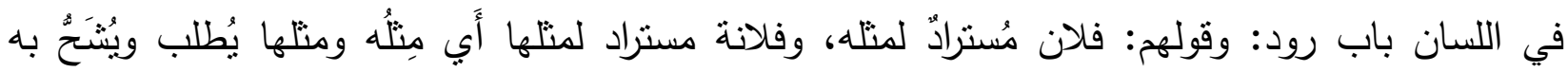

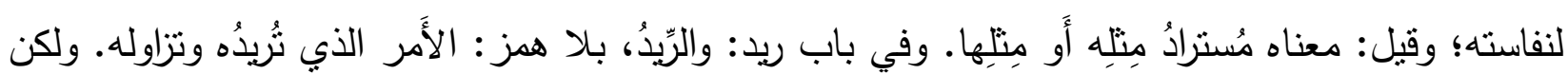
الكاتب استخدمها بصورتها العامية لتكون علامة هوية، ندل على السودانيين، ولغتهم في وصف المحبوب بالمريود، والمحبة/الريدة، وفلان مريود أي محبوب حباً شديدا لا تشوبه شائبة.

وهو علامة تدل على وصف لمحذوف موصوف بصفة جميلة متعلقة بفعل القلب/الدحبة/الريدة، ولكن سبب هذه الريدة الذي يجعله نفيسا، وبلا مثيل، مخبأ في منن الرواية كفعل تتويق، ودعوة لاكتثاق أن هذا الموصوف لا أعداء له، ولكن هل هذا بفعله، أو بأخلاقه؟ وهو علامة ندل نقافيا على أوزان مماثلة لمفعول؛ مثل محفوظ، وربما المعنى الصوفي أنه مختار من اله ليحبه العباد. كلها دلالات مفتوحة تؤكد قدرة الكاتب في التعامل مع اللغة، وامتلاك ناصيتها، وأن العنوان لا يكون ضربة لازب، وإنما هو تفكير؛ وتفكير طويل تأتي بعده العلامة مثقلة بالدالات الثقافية، فاتحة النص لاحتمالات متعددة للمعنى، وتضفي معنى الخلود على ما يكتب.

وثمة عنوانان داخليان في متن رواية مريود؛ هما عثا البايتات، والطاهر ود الرواسي. والعنوان بوصفه علامة لا يفقد معناه البتة بناء على موضعه، ندرك ذلك إذا وقفنا في العنوان (سعيد عثا البايتات القوى). هو عنوان مركب، وعلامة لها مرجعية ثقافية سودانية، فنحن أمام اسم هو سعيد من السَّعْد: اليُمْن، وهو نقيض النَّْس، والسُّعودة: خلاف النحوسة، والسعادة: خلاف الثقاوة. يقال: يوم سَعْد ويوم نحس. وهو 


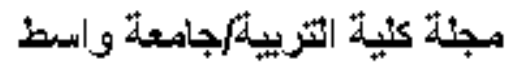

موصوف بصفة هي علامة لهوية سودانية (عثا البايتات القوى) ذات مرجعية ثقافية تدل على الكرم والمروءة والنجدة، وكل القيم النبيلة المطلوبة في الرجولة بصفها قيمة اجتماعية وثقافية. ثم وصفه بعشا البايتات على الجوع (القوى)، وفيه إثارة إلى الطلب العزيز للقوت، والذي يشكل حضوره للمحتاجين إليه سعادة ما بعدها سعادة، لأنه مرتبط بالبقاء. وقبل ذلك هو سعيد؛ مشتق من السعادة. وهي قيمة مطلوبة تدلل على أنه ربما سعيد بهذا الوصف.

وأما الطاهر ود الرواسي، فهو عنوان مكون من ثلاث مفردات زنتها على التوالي: (الفاعل فعل الفواعل) على رد مفردة (ود) الى أصلها (ولد). ربما له دلالة بهذا الترميز الصرفي دلاليا. (الطاهر) من

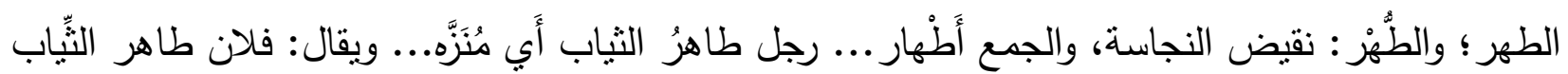
إذاذا لم يكن دَنِسَ الأَخْلاق. والطهر نقاء وصفاء وسلم. (ود) بمعنى ولد، وهي عامية سودانية، وهي مفردة علامة تدل على الهوية. (الرواسي). جاء في اللسان مادة (روس): ورَواسُ: قبيلة سميث بذلك... وفي مادة

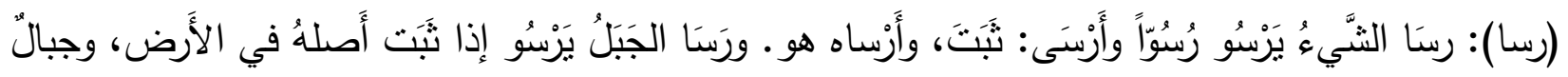

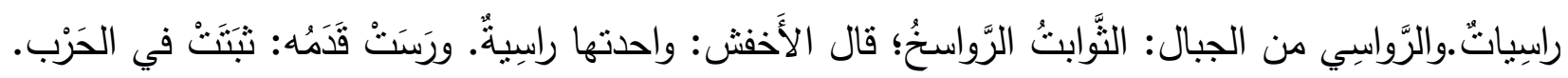

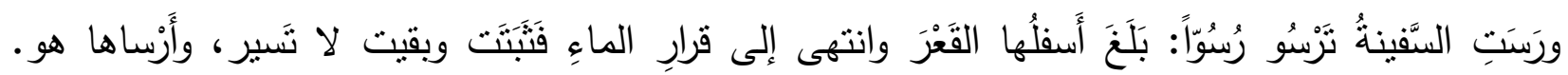
فالمفردة إذن علامة تدل على جمع راس/فاعل، وهو العاقل، وتدل على الرسوّ، أي الوصول والثبات، والعقل والاستعداد.

ـ منسي: إنسان نادر على طريقته: عنوان مركب من خمس مفردات؛ (منسي) اسم مفعول مشتق من

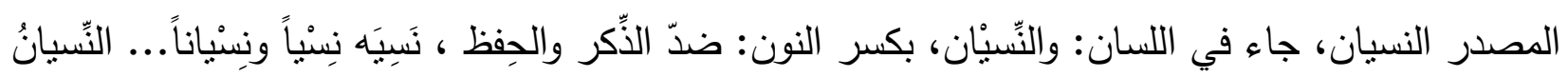

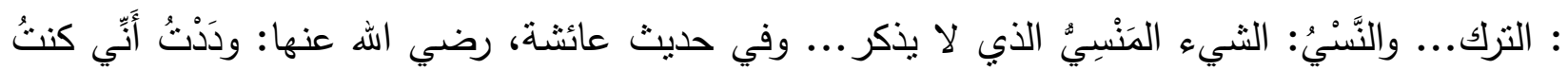

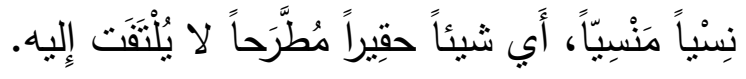

(منسي) علامة تؤشر إلى فعل الذاكرة، وتدل ثقافيا على الإهمال المقصود لقيمة في المفعول، وتدل على الغياب/عدم الحضور في الواقع/المجتمع، وفي الذاكرة الاجتماعية/التقافية. "لم يكم مهما بموازين 


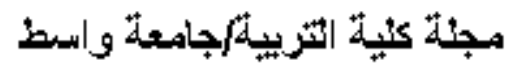

الانيا"منسي/9 ـ والدلالة الموازية هي المذكور ، والمشكور ، والحاضر بقوة بفعله، وقوة شخصيته. "شغل مساحة أكبر مما كان متاحا له، وأحدث في حدود العام الذي تحرك فيه ضوضاء عظيمة"منسي/9.9.

وهو موصوف بجملة (إنسان نادر على طريقته)، وكأن الكاتب استدرك أن هذا الموصوف بالغياب التقافي، هو إنسان بالحضور الاجتماعي، ويمعن في الوصف (نادر)؛ والندرة عكس الوفرة، فهو مثال، وأنموذج، ولكن نلك الصفات هي من فعله/قدرته؛ هو الفاعل (على طريقته). ويحضر تداعي تركيب (على كيفه) العامي السوداني ليؤكد معنى الحرية المطلقة في الفعل. والتركيب عنوان/علامة بارز فيها اسم (منسي)، ثم تحته بالخط الرفيع (إنسان نادر على طريقته)، وكأنه استدرالك يتفضل به الكاتب، ليحل ليثبع به فضول المتلقي؛ نعم هو منسي بكل دلالتها التقافية بوصفها علامة، ولكنه إنسان نادر على طريقته ـ يفرض هذا المعنى (منسي) بطريقته في التواصل مع الآخرين؛ بني جنسه (إنسان). والاستدراك علامة تؤشر ثقافيا إلى تحفيز المتلقي لقراءة النص، وهي القيمة الكبرى للعنوان بوصفه علامة لها مرجعية وظيفية ثقافية أثناء تلقي النص.

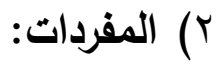

سوف أدرس مفردات الطيب صالح من خلال بنية المفردة ودلالتها ووظيفتها في السياق، ناظراً إلى المفردة قبل دخولها في التأليف، ثم في التركيب؛ لأن معناها سوف يرتبط بما قبلها، وبما بعدها. ولكي أوضح ذلك استعير هذا المثال(r)؛ 1- يجب أخذ الأسد إلى حديقة الحيوانات. r- بجب أخذ علي إلى حديقة الحيوانات.

(أخذ) في المثال الأول تحيل الى معنى قريب من الاعتقال، وبالتالي إلى العقوبة؛ إذا كان السد قد هرب من حديقة الحيوانات، وهذا المعنى يحيل ثقافيا إلى طريقة الاعتقال والوسائل المستخدمة لتتفيذه، وحالة الهياج والخطر المنوقع والترقب المرنبط بالموقف كله. 
أما الحالة الثانية فإن (أخذ) توحي بفكرة الجزاء، أو التعلم، ويفهم أن علياً ربما يعاني خوفا من الحيوانات، وتدل على عناية الأسرة بأبنائها، وتدل ـ أيضا. على تزجية الوقت بالرحلات.

هذا يوضح أهمية السياق الذي تستخدم في المفردة والتي ـ غالبا. ما يعنيها الكاتب، وهو بصدد توجيه رسالة، أو تواصل مع المتلقي، وهو خبير باللغة، ويتمتع بحس نقدي لغوي عال، وهوعلى دراية بما يكتب "أنا أستعمل كلمة (نصارى) عمدا، فهذه هي الكلمة التي استعملها المسلمون، والعرب طوال تاريخهم... هي كلمة حافلة بالمودة والرحمة. عكس كلمة (مسيحيون)"(ז٪). وفي مناسبة أخرى يقول الطيب صالح عن الكاتب (ساميول بيكيت)(\{ ):"لقد أخذ (ساميول بكت) عن (جويس) عنايته باللغة والذهاب بها كل مذهب... وشق لنفسه طريقا نسيج وحده، وقدم رؤيا أدبية مريعة... هذا الكاتب عنده فترات الصمت بين الجمل أهم من الجمل نفسها... وقد ظل في كتاباته يكثف، ويحذف، ويقلل من الكلمات، ويزيد من الصمت... لعل ذلك الكاتب الذي يزن الكلمات بميزان"(؛؛).

والمعنى وليد سياقات هي من طبيعة لفظية... فالكلمة ذاكرة مفتوحة.. إنها تائهة بدون سياق، ولكنها الأساس الذي تستتد إليه ممكنات التأليف؛ فهي جزء من معجم من خصائصده أنه لا يتكلم.... ولكنه يُعدُّ. . مع ذلك ـ خطاباً حول الطريقة التي تستعمل من خلالها ثقافة بعينها. وهذا ما يجعل السياقات أوسع من ممكنات النص المباشرة. وهي بذلك غير قابلة للتحديد... وهو ما يفتح النص على محيطه النقافي، كما هو مودع في مجمل التقعيدات التي تعد الكلمات حاملها الأساس(T)؛

أ. مفردات عربية فصيحة يستخدم الكاتب المفردات الفصيحة، والغريبة بصورة تلقائية سلسة، تجدها منسجمة في سياقها على الرغم من أنها تحتاج ـ أحيانا ـ لمعرفة معناها إلى المعجم ، ولكنه ـ أي الكاتب ـ أدرك ذلك، فوضع سياقا يؤشر للمعنى مباشرة، أو يدور في فلكه. تجد ذلك في كل رواياته محل الدراسة، انظر المفردات(v)؛: (مقرور، دخيلة، العشيرة، يطفر، ضربت، لعمري، مُنْغَرَس، مبيض، فرائص، البتّة، حمأة، الوطيئة، أركبتُ، الكفل، مربّ، الممضّ..... إلخ).

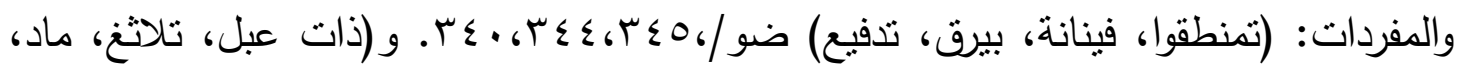




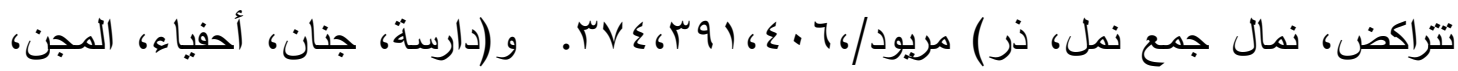

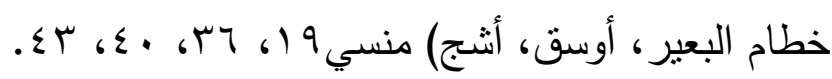

"ولم يمض وقت طويل حتى أحست كأن تلجا يذوب في دخيلتي، فكأنني مقرور طلعت عليه الثمس، ذاك دفء العثيرة، فقد كنت زمانا في بلاد تموت من البرد حيتانها"موسم/ r. " انفجرت هي ببكاء

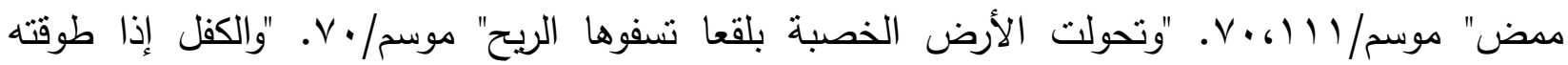

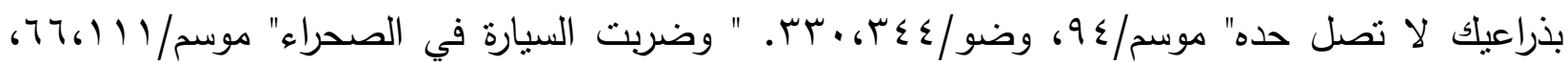

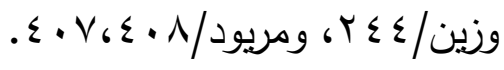

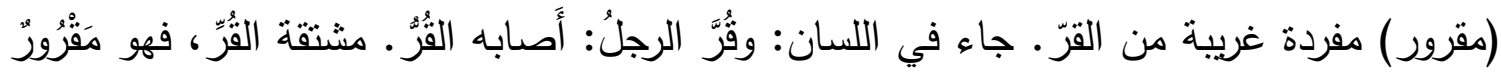

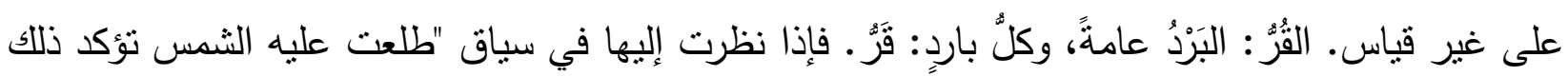
المعنى، وهو ما شعر به . في رأيي . الكاتب فاضاف وصف (طلعت عليه الثمس)، ومن ثم يعقب "ذاك دفء العشيرة". وفي الذاكرة التعبير السوداني (نفخه القُر). في دلالة على البرد الثديد، وهي نتلاقى في النص مع مفردة (غلفاء)، لتكسب مفردة (مقرور) بعدها الثقافي السوداني؛ (مقرور/غلفاء) في ظل سياق حافل بالدفردات ـ ربما ـ الغريبة عن الاستخدام في المرجعية الثقافية للمتلقي السوداني؛ (لعمري، العشيرة، مبيض... الخ)؛ " جاءت الأنباء تترى... أن ابنه يبيت ليله كله في خمّارة"الزين/ بr. ." وكان الظلام المخملي الكثثف يربض على أركان البلد.. "نحرت الإبل، وذبحت الثثران، ووكئت قطعان من الضأن على

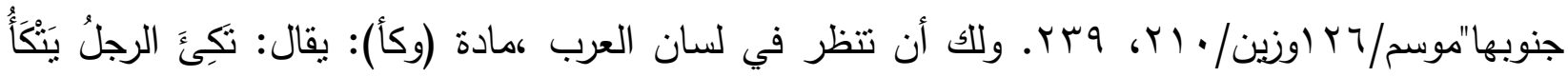

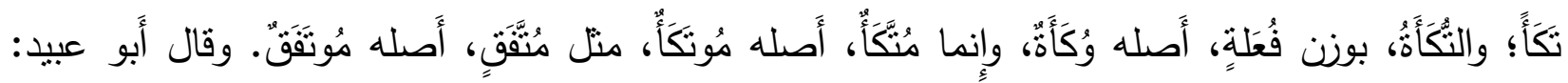

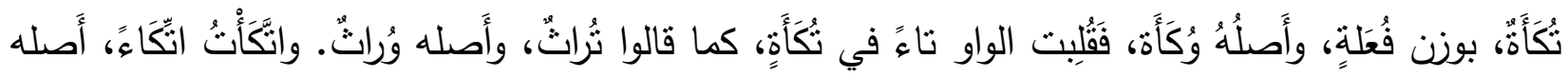

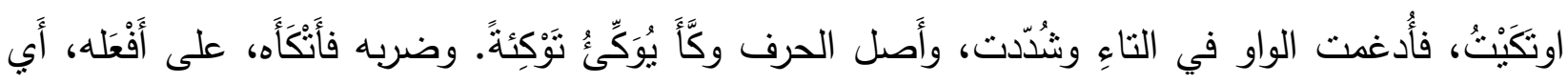

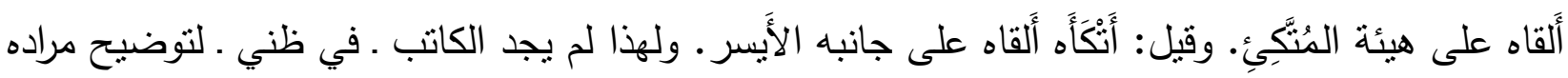
إلا باستخدام تعبير (على جنوبها). 


\section{مجئة كية اتربية مجامعة واسط}

الدفردات علامات لها دلالاتها المعجية، والثقافية، ويحكم ذلك سباق التعبير ، الذي ربما يكون تدفقا لا واعيا من قبل الكاتب، وربما يكون مقصودا. وقد نجح الكاتب في تذويب المسافة بين هذين المنحيين في تلقي المفردات. فهو يقصدها، ولكنه يعبر عن ذلك بتلقائية تجعل المفردة منسبكة تمام في سياقها.

انظر إلى المفردات: (استوعب، الورثاء، ينتزّى، أحفياء، تسامع تدفيعا، نتراكض، ضوّأت، نمال، أحوات)، فأنت تجدها فصيحة ولكن بعضها قليل الاستخدام حتى يظن أنه ابتدعها. "وقفت عند باب دار جدي في الصباح ، باب ضخم عتيق من خشب الحراز، لاثتك أنه استوعب حطب شجرة كاملة"موسم/ 91. الاستيعاب مفردة اقترنت ولزمان بالفهم، والفكر والعمليات العقلية عموما، وقد استخدمها الكاتب بالدلالة نفسها " مصطفى سعيد يا حضرات المحلفين إنسان نبيل استوعب عقله حضارة الغرب"موسم/•..ولكنك تجدها وبكل سهولة، وسلاسة تدل على معنى الاشتمال، والاستهلاك. ودلالتها قوية في هذا السياق، فكأنه لم يترك من حطب الثجرة شيئا، ليثبت معنى الضخامة اللاحق في الوصف. وهذا يؤكد دلالة المفردة معجميا، كما

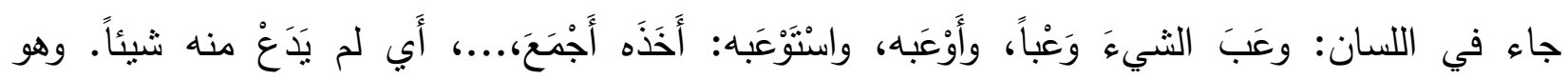
والاستِقِصَاءُ في كل شيءً.

فالكاتب يعرف أسرار اللغة، ويعرف منى يستخدم صيغها التي تزخر بها، مما يدل على مخزون لغوي كبير، يمتح منه متى شاء، وكيفما شاء. ثم إن الكاتب يستخدم جموعا تجعلك تشك في صحتها أول وهلة، فهو يلفتاك برفق إلى قدرته اللغوية، ومعرفته بأسرارها؛ (الورثاء، المراءات، نمال، أحوات). "والناس أمثالك هم الورثاء الشرعيون للسلطة"موسم/ء (1 ـ "كان صوته يطفو كأحوات ميتة طافية على سطح البحر"موسم/1 ـ 1. "وألقيت نظرة موضوعية على الستائر الوردية، والمراءات الكبيرة"موسم/79 179 حجرها، وهدهدنتي زمنا بصوت: إنه دبيب نمال في تال رمال"مريود/؟ ـ ـ ـ كأن الكاتب يقول للك أضف إلى ذخيرتك اللغوبة أن جمع مرآة:مرايا، ومراءات، ـ ولم أجد هذا الجمع مستعملا إلا عنده فيما وققت عليه من مصادر اللغة ـ وجمع حوت: حيتان، وأحوات، ونملة: جمعها نمل، ونمال... إلخ. جاء في اللسان : النَّمْلُ: 
معروف واحدته نَمْلة ونَمَلة، وقد قرئ به فَعَلَّه الفارسي بأَن أَصل نَمْلة نَمُلة، ثم وقع التخفيف، وغلب، وقوله

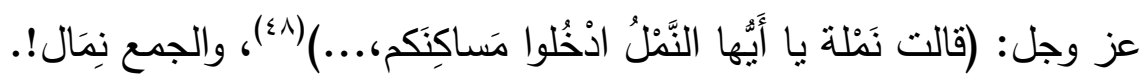

بقي أن أثنير إلى أن الكاتب يكرر مفردات بعينها في رواياته، وهي مفردات علامات تؤشر إلى قيمة نصية، ورسالة دلالية نؤطر العمل الروائي، وتحدد المرجعية النقافية له. ذلك لأن "تراكم المادة المعجية يظهر بدوره النمط النقافي للجماعية العرقية"(9). منال ذلك أن وفرة المفردات المعبرة عن مفاهيم تعالج الزراعة، أو التجارة تعطي إنشارة موثوقا بها إلى حد كبير عن النظام الاقتصادي للسكان"(•). وقد استخدم الكاتب في رواياته مفردات كررها كثثرا، يمكن توضيحها إحصائيا بالجدول التالي: جدول رقم ( (1): يوضح تكرر بعض المفردات في روايات الطيب صالح.

\begin{tabular}{|c|c|c|c|c|c|c|}
\hline المجموع & طنسي إنسان نادر على & |بندر شاه & $\begin{array}{r}\text { بندر شاه } \\
\text { (ضو البيت) }\end{array}$ & عرس الزين & إلى الثمال & المفردة \\
\hline 79 & $\wedge$ & 9 & $\Lambda$ & $r$. & rA & النيل \\
\hline rv & - & ir & r & v & 17 & النخل \\
\hline Y & $r$ & v & 7 & 0 & 7 & زرع \\
\hline MI & v & 0 & Y & 90 & VA & البلد \\
\hline 119 & 11 & $r$. & 1. & $\wedge$ & $\varepsilon 9$ & بحر/ نهر \\
\hline $1 \cdot r$ & 1 & $\Lambda$ & ir & $r$. & 0 . & الأرض \\
\hline
\end{tabular}

يؤشر الجدول إلى أن مفردة (البلد) وهي ود حامد ـ غالبا ـ هي مفتاح النص، ومركزه، وبؤرته مرتبطة بالارض المفتاح الثاني التي محل الزرع، والنيل، والنهر، والبحر ، والنخل، وهي مفردات توضح البيئة الزراعية للمنطقة، ومن ثم هي علامات على الاستقرار والتحضر . 


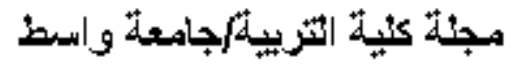

ب. مفردات سودانية: وأعني بها المفردات الخاصة باللهجة السودانية، وهي كثيرة جدا، تصنف الكاتب مبدعا يهتم بالهجته بوصفها هوية، تؤشر دلاليا إلى انتمائه. " والطيب صالح صاحب رسالة سودانية، حمل همّ التعريف بوطنه، حتى عرف وطنه به... فجاءت كتاباته تعريفا في ذاتها، ولكنه سعى بذكاء إلى تمرير كثير من المفردات، والدفاهيم والثخصيات في كتاباته"(ه). وقد عد أحمد البدوي استخدام الكاتب للعامية السودانية معادلا موضوعيا لفقده وطنه، وهذا معناه، أن الكاتب يستخدم المفردات السودانية ليدل على هوية، وعلى انتماء، "العامية السودانية مانلة بروحها وشخوصها كالمسميات: المراكيب، السعدة، السبيطة، القنديل. وفي الثعر وطقوس التزراث الثعبي كالضريرة والدلكة والحريرة، ولهذا المثول دلالة تستجلى في دلالة على أمر يتجاوز اللغة المحضة، ويكمن وراءها، وتكون هي مجرد رمز ينم عنه، دلالة استجلاب معنوي للعزيز المفقود: أيقونة النواصل الحميم، كالمدين المفلس يسعى وجدانيا لاستعادة كنز حرم عمليا وفعلا من اقتتائه"(ro). "استخدام العامية، منطوية على رغبة في استعادة الانتماء إلى نرنيمة غابت من حياة الكاتب، فهو علي الأقل لا يستخدمها في البيت، و لا مجال العمل، أي نوع من التعويض الوجداني عن فقدان السودان ممثلا في عاميته، التي ما ينفك يشعر أنه جزء منها و أنها جزء

$$
\text { منه "(or). }
$$

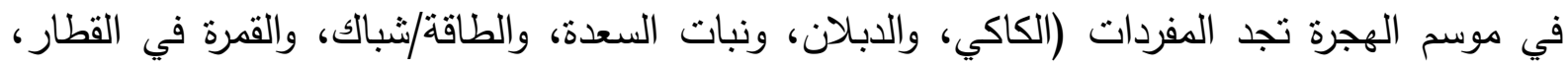
وعجوز كركبة، والجروف، والقيف، وأغلف، والفركة، القرمصيص، والبرش، والمصطبة، والرطانة، والبطان،

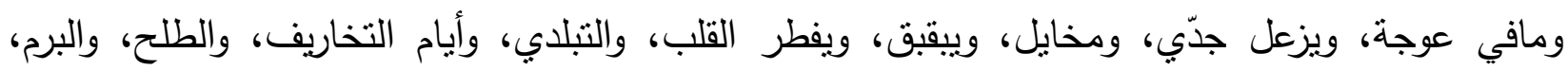

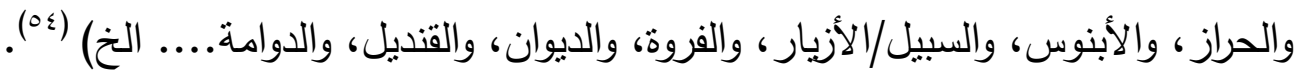

وهي مفردات تكتسب دلالتها من السياق، وهو المعول عليه في كل الروايات لأن المتلقي غير سوداني .

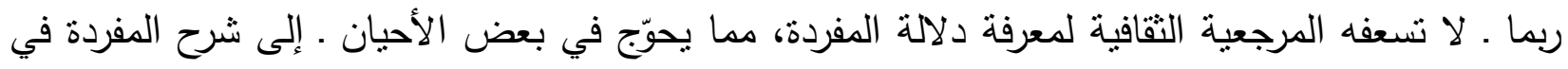
الهامش. ولكن من خلا سياق المفردة يمكن بسهولة ـ الاهتداء الى دلالتها، والكاتب يقدم إعانة واضحة للمتلقي من متل: "البرم، زهر الطلح... الخ"مريود/هبr. وهو يتحدث في سياق (الثنجر)، مما يدخل المتلقي 


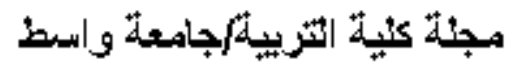

في جو النص معولا على مرجعيته النقافية العربية، التي كتبت بها الأعمال؛ واللغة علامة هوية، ومفتاح تواصل مع النصوص: "مثل نبات السعدة على حافة الجدول"موسم/17 . و "بنت البلد تعمل الدلكة والدخان

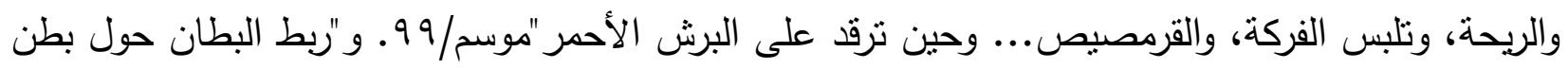
الحمار "موسم/VY I I.

وفي عرس الزين تجد العامية السودانية المفصحة، هي لغة النص، لهذا تجد الكثير من المفردات السودانية، والكثير من أساليب الكلام السوداني، وطرق التعبير التي هي علامات هوية. " استيقظت ثاني يوم

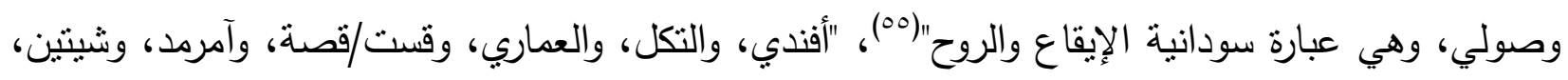

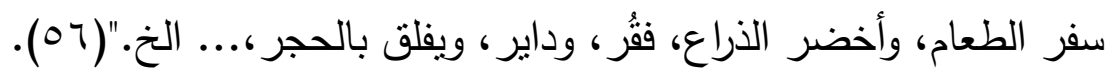
وفي بندر شاه تجد المفردات: "اليئم، واقاشط، ووحلان، وهبد، والسوط، والجبانة، وعتود، واللالوب، والقيف، واللغاويص، وقنت، وهبوب أمشير، الطهورة، حمار خندقاوي، وحمار كورتاوي، وجل، والتمساح

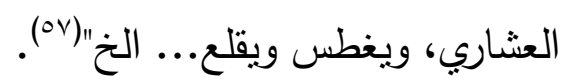

وفي منسي يصعب أن تجد مفردات علامات على هوية سودانية، فهي إما فصيحة رغم الاستخدام السوداني؛ السياقي، وإما فصيحة تماما. وسبب ذلك ـ في ظني ـ أن النص لا يعالج قضايا محلية مثل أعماله الأخرى، وإنما هوعربي يعالج قضايا عربية وعالمية، ولهذا لا تستغرب إذا وجدته يناقش قضية العرب الأولى "فلسطين التي ذكرها 9 Y مرة مقابل •0 مرة لليهود والإسرائليين، و 111 مرة لمفردة عرب، في عمله هذا الذي هو بالأساس سيرة ذاتية لثخصية واقعية، عاشت فترة من حياتها على علاقة بالكاتب، ولهذا أيضا تجد كثرا من أسماء السودانيين الذي تزامن وجودهم في الحياة مع بطل النص، وهي شخصيات حقيقية. فضلا عن أسماء المدن والثخصيات الانجليزية، والعربية في هيئة الإذاعة العربية في لندن، والثخصيات القطرية.

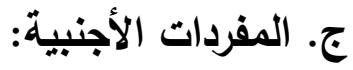

لم يستخدم الكاتب مفردات أجنبية كثيرة في روياته الثلاث الأولى، "استخدم كلمات من الدخيل، مثل (أمنيزيا)، ولكنه في الصفحة التالية يستخدم الكلمة العربية التي تؤدي المعنى نفسه)، فقدان الذاكرة (ومنلها 


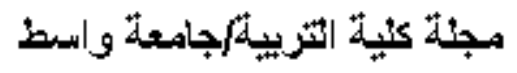

كلمة) برنيطة (التي وردت معها في الصفحة نفسها كلمة (قبعة). وهناك كلمات من الدخيل استخدمت بنصها مثل : مكنات الماء وإسكتشات وميليودرامية(^ه). ولكنه أكثر من استخدامها في منسي بحكم الفضاء المكاني الذي تجري فيه أحداث الرواية، وصفات الثخصيات وعلاقتها بالكاتب وعمله في بريطانيا وقطر .(09) r

يستخدم الكاتب طريقته الخاصة في الوصف مدركا تماما إمكانات اللغة، وقدرته في التركيب، فهو لا يكتفي · في الغالب • في وصفه بمفردة واحدة، دائما ما يأتي بمفردنين مقترنتين( • ()، ليعطي الوصف قوته، كأنه يريد من المتلقي ألا ينسى ذلك الموصوف، ثم يبين قدرته، ومعرفته ل لأسرار اللغة. مستتدا الى ثقافة رصينة "وملنا إلى أنه أفاد من براعة الرباطاب في الوصف، وعقد المقارنات البديعة بين الأثياء، كرافد متح منحاه الدقيق في الملاحظة، وإجادة الوصف"(1).

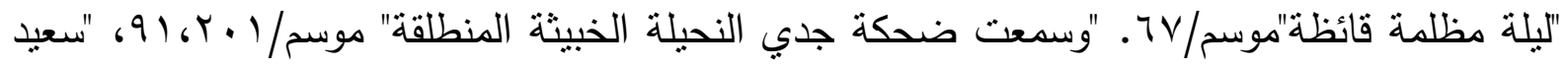
الوسخان العفنان"ضو/ / r . "وكان وجه الزين مستطيلا ناتئ عظام الوجنتين... جبهته بارزة مستديرة، عيناه صغيرتان محمرتان"الزين/V ) ، "كل ذلك يظهر في وجهه الحاد التقاطيع المليء الأخاديد"منسي/ror.

ثم إن الكاتب يظهر عناية خاصة بوصف الأصوات: "حوافر الحمير تحدث نغما نشطا متحفز|"مريود/Vדr، "بكاء ممض محرق"موسم/•V، "ضحكة صغيرة ضحلة"مريود/9 צr، "ضحكة نحيلة

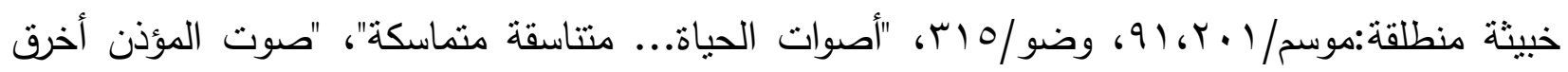

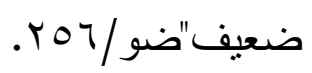

فالكاتب يستخدم طاقة المفردات كاملة، فالنغم النشط هو النغم الصاخب الذي يملأ المكان بايقاعاته وموسيقاه، ووصف كهذا لاثك أنه يدفعك للحركة (متحفز)، تتحرك في مكانك مستجيبا للنغم. والبكاء

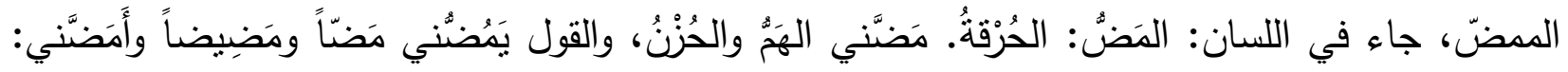
أَحْرَفَني وشقّ عليّ. وهي مفردة نوحي بالقهر، وعدم القدرة على الانطلاق في البكاء من شدة الألم النفسي، 


\section{مجئة كية اتربية مجامعة واسط}

وطبيعي أن يكون محرقا ليدل على قوة الفاعل؛ (البكاء الداخلي). على العكس من الضحكة المنطلقة مع نحالتها، وخبثها، والانطلاق انفتاح لأسارير الوجه، وعلامة قبول للآخر. على أن الكاتب يكثر في وصفه من لهن صيغتي (فاعل، وفعيل)؛ اسم الفاعل والصفة المشبهة باسم الفاعل، ويمكن ملاحظة ذلك من الجدول التالي:

$$
\text { جدول رقم (ץ):بوضح استخدام الكاتب لصيغتي (فاعل، وفعيل): }
$$

\begin{tabular}{|c|c|c|c|}
\hline المصدر & صيخة فعيل & المصدر & صيغة فاعل \\
\hline موسم/9 • & الظلام كثيف وعميق & موسم/V V & ليلة مظلمة قائظة \\
\hline زين/· | & نحيلا هزبلا & زين/v| & وجه ناتئ العظام \\
\hline ضو/r •r & صوت غريق & ضو/· • • & نهذ طالع \\
\hline مريود/9 דr & ضحكة صغيرة & مريود/「هم & يشرب الغادي والرائح \\
\hline منسي/VY & كانت شيري وسيمة & منسي/ץ & ممسكا بخطام البعير \\
\hline
\end{tabular}

والفرق بين الصيغتين في الدلالة؛ هو "أنَّ فَعيلا للسَّجايا والطبائع ولا تكون لغير ذللك، أما اسم الفاعل

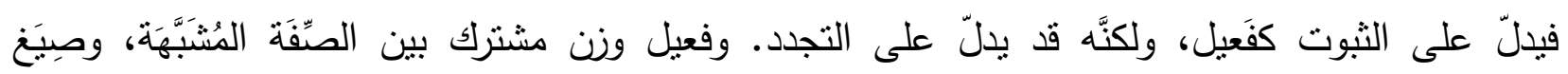
المُبالَغَة، فصيغة فعيل هي من أبنية الصِّفَة المُشَبَّهَة الدالَّة على الثبوت، فيما هو خلقة، أو بمنزلتها؛ كطَِيل،

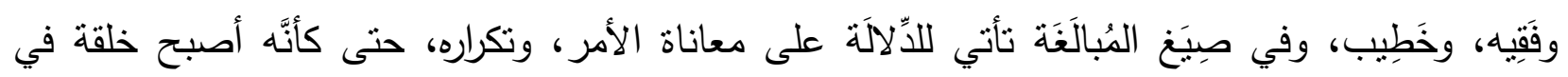

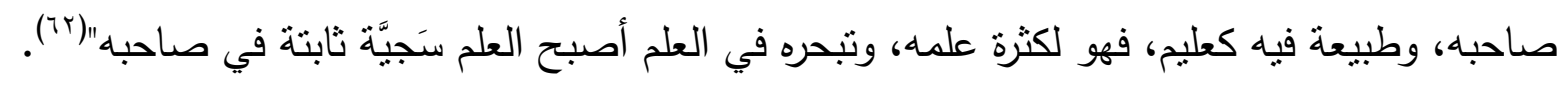

ومن ثمّ كان الذي يستخدم صيغة (فاعل) يرمي إلى بيان أمرين: (المعنى المجرد مطلقاً، وصاحبه)، دون اهنمام ببيان درجة المعنى، قوة وضعفاً، وكثثرة وقَّلة، بخلاف الذي يستخدم (صِيغَة مُبَالَغَة فعيل)، فإنَّهَ

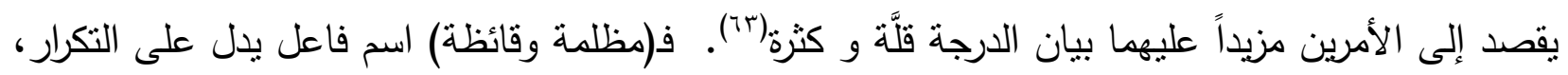
والتجدد؛ تكرار الإظلام، وشدة الحر في هذا الثهر من السنة، بينما (كثيف وعميق)، صفة مشبهة تدل على المبالغة في الإظلام، والإيحاء بتأثنر ذلك في النفس؛ (عميق)، لندل على الثبات المقلق، وكأنه لا إنجلاء له 


\section{مجية كيلة |تربية مجامعة و اسط}

والكاتب خبير بشخوص رواياته، وأوصافهم، وصفاتهم، وفي فعل الكتابة يظهر خبرة ودراية بالوصف

الخاص بكل شخصية، يحشد لها الصفات التي تتاسب معها، وصورتها في العمل الروائي: يتحدث محيميد عن محجوب، يوم وفاة مريم في رواية مريود: "لكننا كنا أعزّ إنسانين لايها، أنا قطب أحلامها مستقبلا في المدينة، ومحجوب أخوها الأوحد بين أربع بنات؛ مريم صغراهن"مريود/9 ؟ . ثم يصف محجوب: "نظرت إليه وسط الجمع ذلك المساء... غاضبا شرسا كأن الموت خصم أرسلته الحكومة، يأمر ، وينهي بصوت أخرش... كان زعيما مطلق اللسان... نشطا متحفزا كحيوان مفترس يتأهب للانقضاض في أية لحظة، وسلطان الموت لا يطال"مريو/9 9 . ثم يصق نفسه في ذللك اليوم: "أما أنا فقد كنت حزينا بشكل آخر ، كنت أراها على موجة تسافر وتعود، والدنيا تبتسم بوجه طفل، عيناها العسليتان تزحمان الوجه، وحاجباها النبيلان ينعقان فوقهما، وثغرها منل برق يشيل ويحط... وأنا أحس في قلبي بفجيعة منل الفرح"مريود/99 ب. ويمكن أن نرى الوصف بهذه الصورة لترى زاويتين للنظر والتقاط الصور :

جدول رقم (r): يوضح وصف محجوب ومحيميد

\begin{tabular}{|c|c|}
\hline محيميا & محجوب \\
\hline 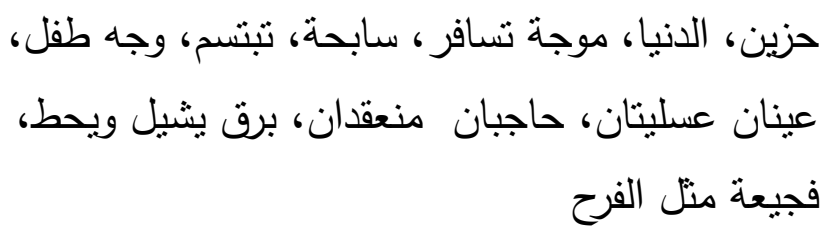 & وينهي، صاضب وشرس، الموت، الحكومة، يأمر \\
\hline
\end{tabular}

كلاهما يعبر عن حالة حزن؛ هي فقد مريم العزيزة لكليهما، ولكن بمفردات لها طاقات تعبيرية عالية في تصوير كل شخصبة نتاسب تماما والثخصية محل الوصف. ولا شك أن المبدع يتميز بطريقة وصفه، وتوظيفها؛ بنائيا، ودلاليا، مما يجعل الوصف شبكة دلالية منظمة بقوة، كما أن المقطع الوصفي في النص من شأنه أن يبرز الوظيفة البنائية، والدلالية التي يريد الكاتب إعطاءها للوصف(گ`)، مفسحا المجال للمتلقي ليتواصل مع لغته، استتادا الى مرجعية ثقافية تعطي للنص قيمة وجوده الاجتماعية، ومن ثم مشروعية رسالته التي يريد أن يبثها عبر وسيط هو هذه اللغة. 


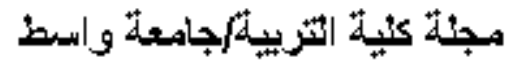

التركيب:

وأعني به الجملة، وسوف أقف معرفا الجملة، وكيف استخدمها الكاتب في رواياته للتعبير عن أفكاره، وكيف يتواصل مع المتلقي من خلال مرجعية نقافية في ظل لغة لها قواعدها، وقوانينها التي ربما تحكم المعنى، وتوجهه إلى غير مراد الكاتب.

الجملة: هنالك دراسات كثثرة حاولت تعريف الجملة؛ لغة واصطلاحا، قديما، وحديثا(70)، وهو شأن اللغويين، وما يهمنا في هذه الورقة ينحصر في معنى الجملة بوصفها علامة سيميائية، تؤشر إلى مرجعية ثقافية، تؤمن عملية النواصل بين النص والمنلقي، من خلال نظام لغوي؛ هو عمل روائي يشكل خطابا سرديا؛ "والخطاب هو ما تركب من مجموعة متتاسقة من المفردات لها معنى مفيد؛ هذا؛ هذا التتاسق بين مجموعة مفردات وفق نظام/بنية، هو ما أسميه الجملة. فالجملة هي الصورة اللفظية الصغرى للقول؛ أو هي الكلام الموضوع للفهر والإفهام، وهي نتيّن صورة ذهنية كانت قد تآلفت أجزاؤها في ذهن الكاتب الذي يسعى إلى نقلها - حسب قواعد معينة، وأساليب شائعة- إلى ذهن المتلقي، ولا يكون الكلام تاما، والجملة مفيدة إلا إذا روعيت فيها شروط خاصة؛ منها ما يعود إلى المنطق، ومنها ما يعود إلى اللغة وسلتطها/قيودها"(TI").

وبالنظر إلى بنية اللغة فهي مركب يؤدي المعنى بطريقتين، وهو ما عرف بقسمي الجملة؛ الاسمية والفعلية. ومن ثم يستدعي هذا التقسيم الرجوع إلى أصل التركيب، وهو المفردات المرتبطة ببعضها بعضا في سياق، وفق نظام للتعبير عن فكرة ذات معنى تام، والمفردات علامات لغوية وثقافية، وهذا ما يكسب الجملة الوصف ذاته. مع اختلاف سياق المفردة الذي تحكمه الجملة، عن سياق الجملة الذي تحكمه بنية النص. وهذا يعطي الدراسة مشروعية الوقوف عند الجملة، وكيف استخدمها الطيب صالح في رواياته؛ وما أثز ذلك في الهوية السودانية من خلال المضامين، والرسائل المبثوثة في الأعمال الروائية للكاتب، بواسطة بناء لغوي ذي مرجعية نقافية لا تخلو من انتماء لجماعة ما، وبالتالي هوية ما. 


\section{مجئة كية اتربية مجامعة واسط}

والفرق بين الجملة والاسمية والجملة الفعلية، هو أن الجملة الاسمية تدل على الثبات

والدوام/الاستمرار، والجملة الفعلية تدل على معنى التجدد والحدوث؛ لأنها مرتبطة بالفعل الذي يكسبها دلالة الزمن. والثنيء نفسه تكتسبه الجملة الاسمية التي خبرها جملة فعلية. ولهذا فإن الجملة الاسمية في دلالاتها تتسع لما لا تدل عليه الجملة الفعلية؛ من التأكيد والمبالغة(YV)، وذلك باستخدام المؤكدات. وكما هو معروف فإن الجملة الاسمية تتكون من مبتدأ وخبر؛ نحويا، ومن المسند إليه والمسند. والجملة الإنشائية،(طلبية وغير

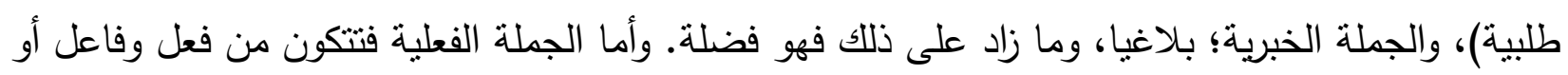
نائب فاعل، وما زاد عن ذللك فهو فضلة(^^. وأن المبتدأ في الاسمية مقدم على الخبر أصالة. وأن الفعل في الفعلية مقدم على الفاعل، أو نائبه. التركيب في روايات الطيب صالح:

"وجاءت أمي تحمل الثناي، وفرغ أبي من صلاته وأوراده، وجاء، وجاءت أختي، وجاء أخواي، وجلسنا نشرب الثاي"موسم/؟r. جملة فعلية حكمت فعل السرد/الكتابة؛ فعلها (جاء) فعل ماض تكر أربع مرات، ليدل على نأكيد هذا المجيء، ويؤشر، بوصفه علامة، إلى فرح المحتفى به بفعل المجيء من أفراد الأسرة، المتبين في النص كبما- بحسب الأهمية؛ (الأم، ثم الأب، ثم الأخت، ثم الأخوين)، ويفرض ذلك حرف الواو الذي يدل على التعاقب بمعناه اللغوي، ومعناه النفسي. والفعل الماض علاهة تدل على قوة الذاكرة لدى المتكلم، وفيها نوع من إنراك المنلقي في الحنين إلى أيام جميلة. والفعل (جاء) نأخر في الجملة الثانية؛ (وفرغ أبي... وجاء)، ليدل على أن فعل المجيء يأتي بعد أداء الفريضة، هي علامة على صلاح الوالد، وتؤشتر إلى أنه يعلي من قيمة فعل الآخرة؛ (العبادة؛ الصلاة والاوراد)، مقابل فعل الدنيا (المجيء إلى شرب الثاب).

وفي النص فعلان مضارعان (تحمل، ونشرب)، ونحويا هما جملتان تدلان على الحال، والجملة الفعلية تدل على معنى التجدد والحدوث، وهي بهذا ندل على أن الأم يتجدد حملها للشاي كل صباح، في تجدد للفعل كل يوم، ولكنه ليس ثابتا، ومستقرا هذا الفعل فيها، وكذلك شرب الثاي حال حادث، ومتجدد، مع 
زمن الفعل المضارع المنفتح على المستقبل، ليصبح علامة على عادة سودانية هي شرب الثاي كل صباح في جماعة، يؤكد ذلك الضمير (نا) في الفعل (شربنا)، والدلالة الثقافية صورة حميمة مشبعة بعاطفة الأسرة، وفيها تأشير إلى الارتباط الأسري، والاعلاء من قيمته، لأنه ينعكس على بناء المجتمع ككل، يؤيد ذلك: "جبت البلد طولا وعرضا معزيا، ومهنئا"موسمه ه. كل ذلك بتحريض من الأم؛ المفردة العلامة، التي تدل على

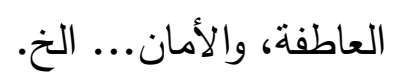

وسوق يتضح استخدام الكاتب للجملة بنوعيها في هذا النص من رواية موسم الهجرة الثمال: " إنتسي أترك زوجتي وولدي وكل مالي من متاع اللنيا في نمتك، وأنا أعلم أنك ستكون أميناً على كل شيء. نوجتي تعلم بكل مالهي، وهي حرة التصرف. إنسي واثثق بحكتها . ولكنتـي أطلب منك أن تؤلدي هذه الخدمة

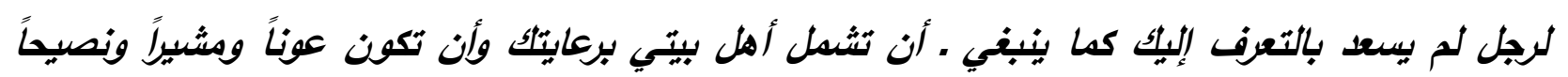
لولدي، وأن تجنبهها ما استطعت مشقة السفر. جنبها مشقة السفر. وساعدها أن بنشآ نشأة عادية

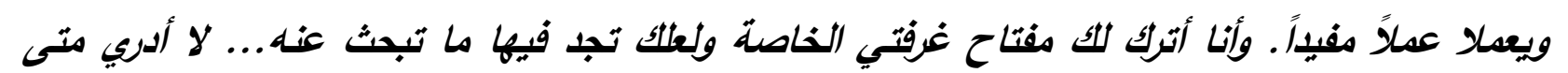
أذهب يا صديقي ولكتني أحس أن ساعة الرحيل قد أزفت، فوداعاً"موسم/شv. ويمكن النطر إلى الجمل وفق الجدول التالي:

\begin{tabular}{|c|c|}
\hline جملة فعلية & جملة اسمية \\
\hline أن تؤدي هذه الخدمة & إنني أترك \\
\hline أن نشمل أهل بيتي برعايتك & وأنا أعلم \\
\hline أن تكون عونا & إنك ستكون أمينا \\
\hline أن تجنبهما مشقة السفر & زوجتي تعلم \\
\hline جنبهما مشقة السفر & وهي حرة \\
\hline ساعدهما أن ينشاً & إني واثق \\
\hline ويعملان عملا مفيدا & ولكنني أطلب منك \\
\hline اذا لم تستطع أن تقاوم & أنا أترك للك مفتاح غرفتي \\
\hline
\end{tabular}




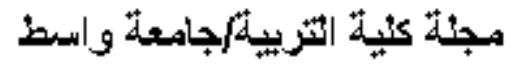

لعلك تجد فيها

وصية محكمة الصياغة، والبناء، محددة اللغة، وواضحة المعنى، لا مجال فيها للبس، مليئة بالجمل الاعتراضية التي اقتضها ضرورة التوضيح، فالمقام مقام وصية، وسياق الكلام يفرض هذا النوع من الجمل. وهي ـ الوصية ـ علامة هوية في لغتها تؤشر إلى مهنة المحاماة في حقل القانون.

تبدأ بجملة اسمية خبرية مؤكدة، هي علامة إقرار قانوي في ثقافة المتلقي: "إنني أترك زوجتي وولدي وكل ما أملك..... من متاع الدنيا...". ثم تتوالى الجمل الاسمية، كما هو موضح في الجدول، لتدل على الثبات والاستمرار في فعل التزك، فهو أمر لا علاقة له بالزمن، ولا بالتجدد، وأنما ثبت أنه نرك وصية مختومة بالثمع الأحمر؛ علامة التقافة التي تدل على خطر فتح المظروف لمن ليس مخول له فعل ذللك. وفيها دلالة على التأكيد على الفعل حتى لا يحدث أدني شك في أنه نرك هذه الوصية لاي سبب خارجي، وإنما هو بكامل قواه العقلية يفعل ذلك. لأنه يدرك أن المقام مقام شرف؛ زوجة وأبناء في مجتمع يحدد علاقة

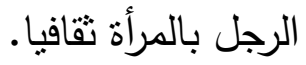

أما الجملة الفعلية، فيلاحظ أنه بدأها (بأن) المصدرية: "أن تؤدي...". وهي ما يمكن أن يؤول بالمصدر (تأدية)، والفاعل دوما هو المخاطب. والفعل المضارع هو فعل التجدد الآني، والمستقبل.

وكثيرا ما يستخدم الكاتب جملا اعتراضية ليوضح فكرة ما، أو يحدد مقصوده حتى لا يحدث لبسا ربما يربك المتلقي، أو يستخدم الجمل الاعتراضية -بخاصة في منسي- ليدل على الدعاء: "ليتتي -غفر الله

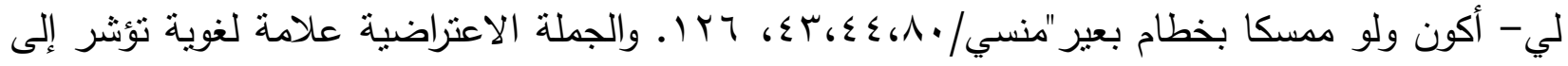
دلالات ثقافية، تحكم علاقة المنلقي بالنص، وتربطه به بفعل الكاتب، وتوجهه، وهي بهذا علامة تنقي أثز الكاتب واضحا في النقافة؛ المرجعية التي تسمح له بايصال خطابه للمتلقي. والطيب صالح -هنا- تميز بأسلوب يختط مسارا يمتد فيه بين تقرير صوغه، وفاعلية أثره، وعلى قدر دلالته، واستجابة المتلقي له تتوقف بائ

قيمته، ومدى تفرد الأديب(79). 


\section{مجية كيلة |تربية مجامعة و اسط}

\section{الخاتمة}

وظّف الطيب صالح الكاتب إمكانات اللغة في أعماله الروائية ليوصل رسالته، وليتواصل مع المتلقي من خلال المفردات والتركيب والصفات، استنادا إلى مرجعية ثقافية مشتركة، ابرزت أثز الكاتب في هذه التقافة بوصفها علامة هوية. فقد استخدم العنوان علامة لسانية، وسيميائية، غالبا ما تكون في بداية النص . لها وظيفة تعيينية، ومدلولية، ووظيفة تأثيرية ثقافية أثناء تلقي النص.(•) وقد وفق الكاتب في استتفاد الإمكانية الدلالية في استخدام العنوان علامة ثقافية، نؤشر إلى قدرته الابداعية واللغوية، وإلى احترامه للمتلقي بوصفه مبدعا ثانيا للنص، ومن ثم يوصف النص بالخلود.

استخدم الكاتب مفردات بسيطة وواضحة المعنى . غالبا. ولكنه كان يختار مفرداته بعناية واضحة، فهو ربما يعلم علم اليقين "أنك ترى الكلمة تروقلك وتؤنسك في موضع، ثم تراها بعينها تثقل عليك، وتوحثك

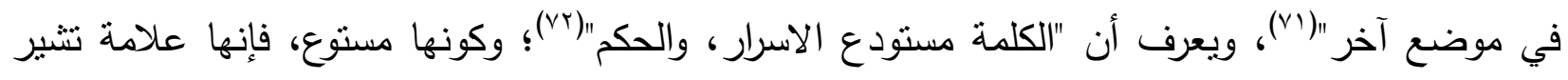
إلى مضامين الطاقة، والامداد الاستراتيجي الذي إذا انقطع يشكل خطراً على الحياة، ولهذا يكون الحرص دائما على بقائه ممتلئا. وكذلك الكلمة/المفردة؛ فهي مليئة بالدلالات معجمبا، وتقافيا في امتياح دائم من مرجعية المتلقي الثقافية. فهو يستخدم المفردات الفصيحة، والغريبة بصورة تلقائية سلسة، تجدها منسجمة في سياقها على الرغم من أنها تحتاج ـ أحيانا . لمعرفة معناها إلى المعجم ، ولكنه ـ أب الكاتب ـ أدرك ذلك، فوضع سياقا يؤشر للمعنى مباشرة، أو يدور في فلكه. واستخدم المفردات الخاصة باللهجة السودانية، وهي كثيرة جدا، تصنف الكاتب مبدعا يهتم بالهجته بوصفها هوية، تؤشر دلاليا إلى انتمائه. " والطيب صالح صاحب رسالة سودانية، حمل همّ التعريف بوطنه، حتى عرف وطنه به. ولكنه لم يستخدم مفردات أجنبية كثيرة في روياته الثلاث الأولى، فقط تم ذلك في منسي لطبيعة الرواية.

والكاتب خبير بشخوص رواياته، وأوصافهم، وصفاتهم، وفي فعل الكتابة يظهر خبرة ودراية بالوصف الخاص بكل شخصية، يحشد لها الصفات التي تتاسب معها، وصورتها في العمل الروائي. فهو يستخدم 
طريقته الخاصة في الوصف مدركا تماما إمكانات اللغة، وقدرته في التركيب، فهو لا يكتفي . في الغالب . في وصفه بمفردة واحدة، دائما ما يأتي بمفردنين مقترنتين، ليعطي الوصف قوته.

يستخدم الكاتب الجملية بنوعيها ليدلل على قدرة عالية في استخدام اللغة، وكثيرا ما يستخدم الكاتب جملا اعتراضية ليوضح فكرة ما، أو يحدد مقصوده حتى لا يحدث لبسا ربما يربك المتلقي، أو بستخدم الجمل الاعتراضية -بخاصة في منسي - ليدل على الدعاء.

\section{النتائجج}

1. المفردات علامات لها دلالاتها المعجمية، والثقافية، ويحكم ذلك سياق التعبير. r. اضاف الطيب صالح تعابير جديدة ومفردات الى قاموس النقافة السودانية تركت بصمة على الهوية.

r. استفاد الطيب صالح من المرجعية الثقافية للمنلقي، ومرر كثيرا من القيم والافكار عبر نصوصه السردية.

ع. استطاع الطيب صالح ان يخط طريقا خاصا به في الكتابة السردية (التركيب، والوصف، والتصوير )، جعلت أعماله تكتسب صفة الخلود. 


\section{التوصيات}

ا ـ توحيد المصطلح في حقل الدراسات النقدية عموما واللسانية على وجه الخصوص. r. توسيع دائرة النقد الثقافي في الجامعات العربية. r. الاكثار من الترجمة للتواصل مع المنتوج العالمي في مجال الادب عموما والنقد خصوصا. ع. الاهنمام بالمواقع المتخصصة في النقد على الثبكة العنكبوتية لضمان نواصل النقاد العرب مع بعضهم بعضا.

'- جاسم محمد جسام. مسارات في النقد الأدبي الحديث من التاسيس الى التجريب. دار ميزوبوتاميا. ط: (، بغداد، ا ـ بم. صטיז.

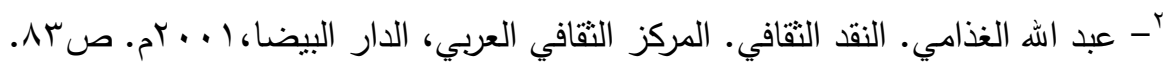

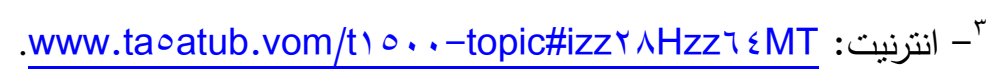

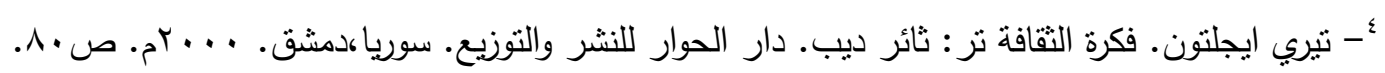

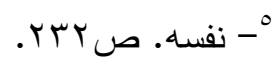

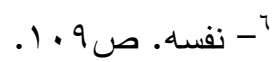

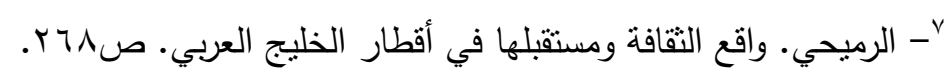

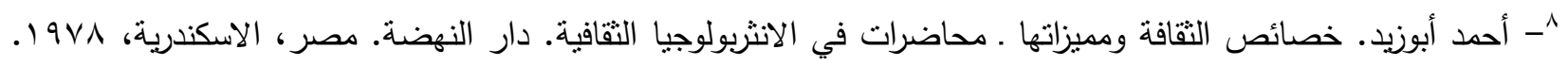
ص ص

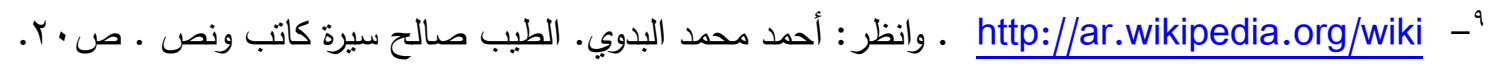

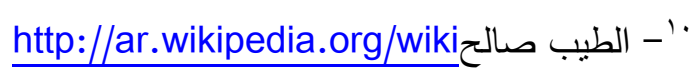

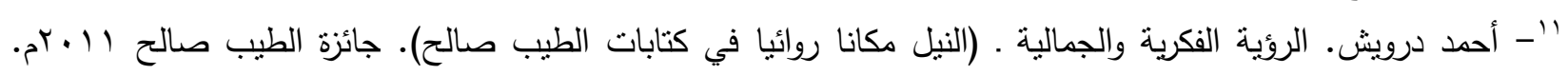
ص י. 
ז' - "يروق لبعض المرتمين بأدب الطيب صالح ـ وربما شاركهم الطيب نفسه ـ أن يجعل (منسي: انسان نادر على طريقته)

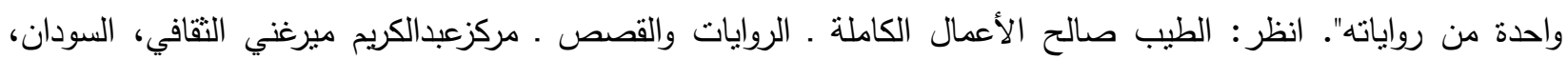

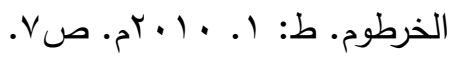
http://ar.wikipedia.org/wiki

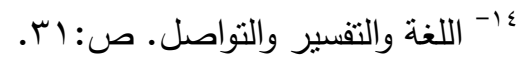

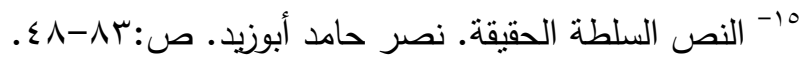
14- التحليل اللغوي للنص، مدخل إلى المفاهيم الأساسية والمناهج. كلاوس برينكر • تر : سعيد حسن بحيري. مؤسسة

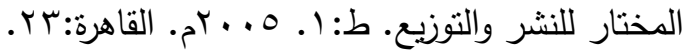

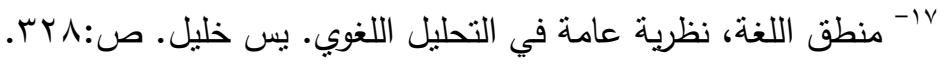

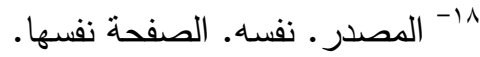

19- العلامة، تحليل المفهوم وتاريخه. إمبرتو ايكو. تر : سعيد بنكراد. مراجعة: سعيد الغانمي. المركز الثقافي العربي. ط: ا. . . . .

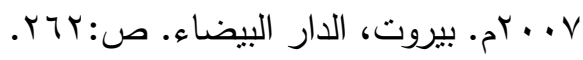
.r. اب- بناء الواقع الاجتماعي، من الطبيعة الى الثقافة. جون.رز سيرل. ترجمة وتقديم: حسنة عبدالسميع. مراجعة: إسحق عبيد.

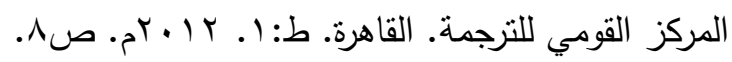

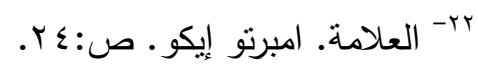

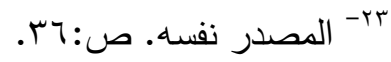
م 9.9 9: 9.9 (Y TOr (1)

9r- النص السلطة الحقيقة. نصر أبوزيد. ص:49. 19 1.

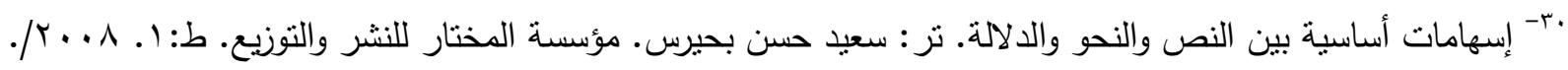

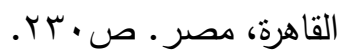

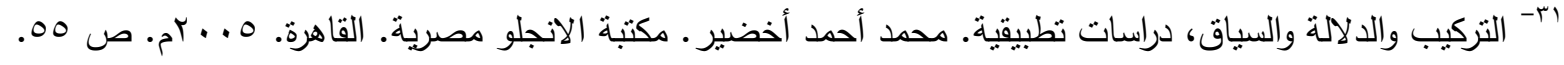

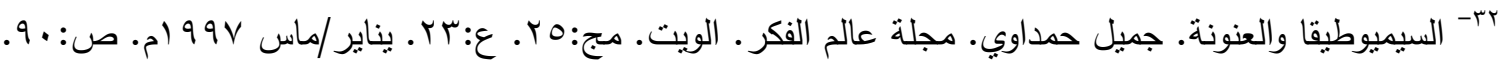
ب - هذا الترتيب.بناء على ترتيب الروايات في (الأعمال الكاملة للطيب صالح. منشورات مركز عبدالكريم ميرغي الثقافي، والذي اعتمده المصدر الرئيس لرويات الطيب صالح محل الدراسة. ايلول \& 1 ب. 


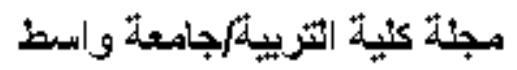

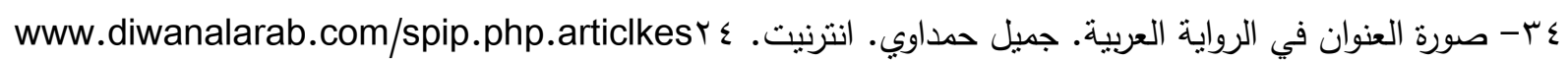

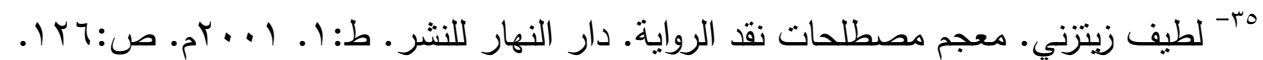

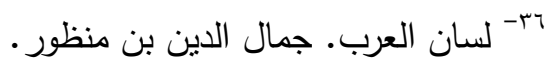

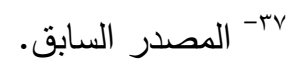

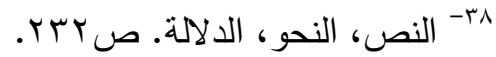

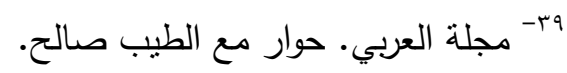

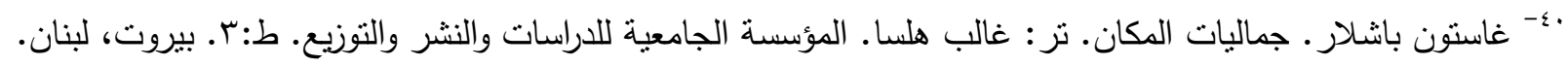

$$
\begin{aligned}
& \text { ص:ص: }
\end{aligned}
$$

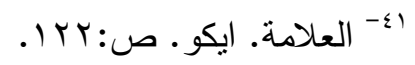

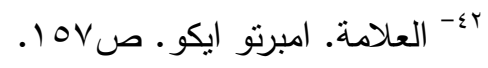

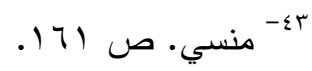

ع - صمويل باركلى بيكيت (بالإسبانية:Samuel Barclay Beckett) ولد في مدينة دبلن أيرلندا) في זا إيريل عام 7 . 9 ام. هو كاتب مسرحي وروائي وناقد وشاعر أيرلندي. وواحد من الكتاب الأكثر شهرة والذين ينتمون للحركة التجريبية الادبية في القرن العشرين ولحركة حداثة الانجلو . وكان رمز من رموز مسرح العبث و واحد من الكتاب الأكثر تأثيراً في عهده. وكان يكتب أعماله باللغتين الفرنسية والاتجليزية. شهد وجود الروائي الثهير جيمس جويس (James Joyce). وعمله الأكثر شهرة في انتظار جودو (Esperando a Godot) تتميز اعماله وتعتمد وبشكل كبير علي الكآبة والسواد وتتجه دائماً نحو البساطة. ووفقا لبعض التفسيرات لنوعية أعماله، فهو بالفعل يميل إلي التشاؤم حول وضع الإنسان. وهكذا ومع مرور الوقت أصبحت اعماله تدريجيا أكثر أيجاز. وفي ب ب ديسمبر 1919 مات بيكيت بعد تعرضه لأزمة في جهازه التنفسي. .http://ar.wikipedia.org/wiki 1

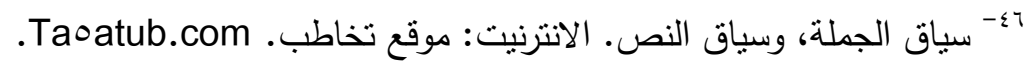

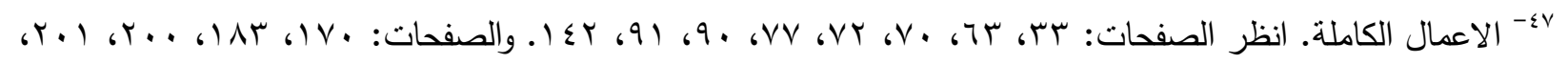
• (Y، Y والصفحات:YOA

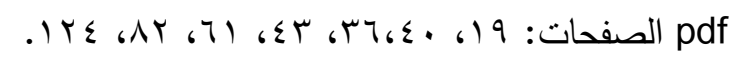

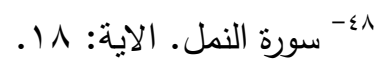
وء- اتجاهات البحث اللساني. مبلكا افيتش. تز : سعد عبدالعزيز مصلوح، ووفاء كامل فايد. المجلس الثقافي. ط:؟. . . . rم. صAר r. • 0 نفسه.

ايلول ؛ 1 ب. 


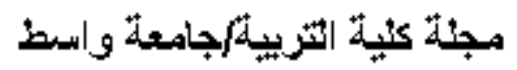

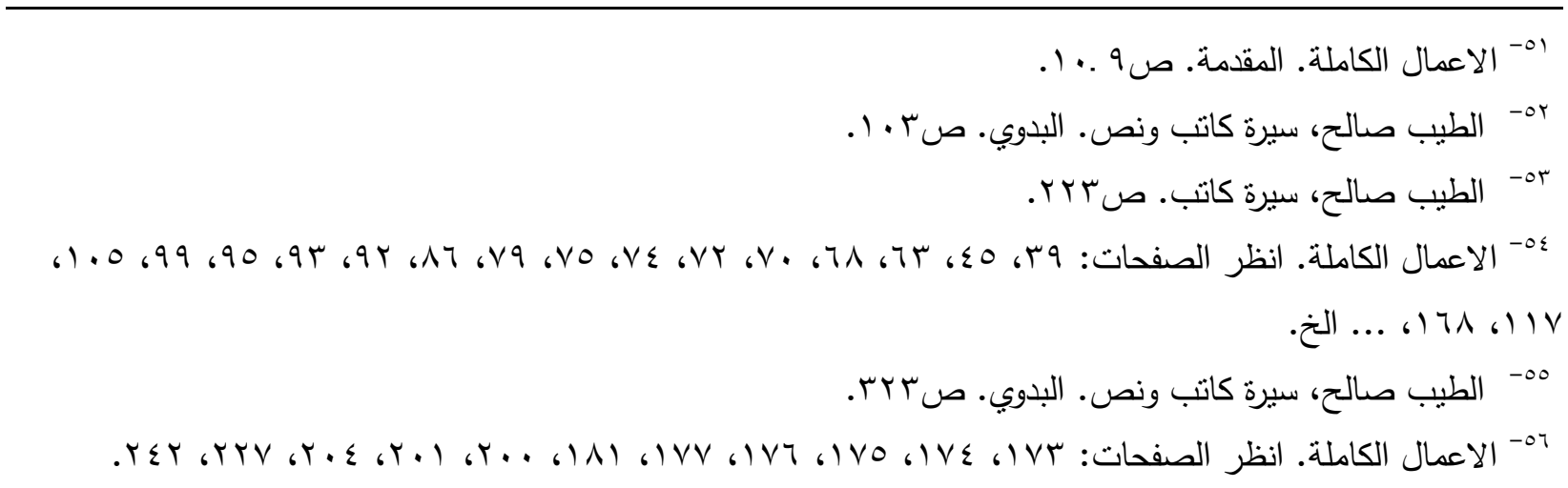

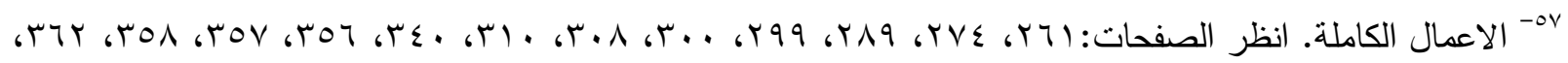

. الخ

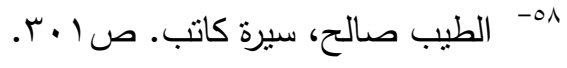

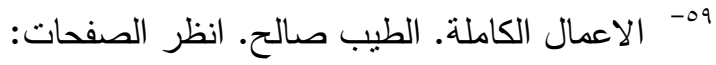

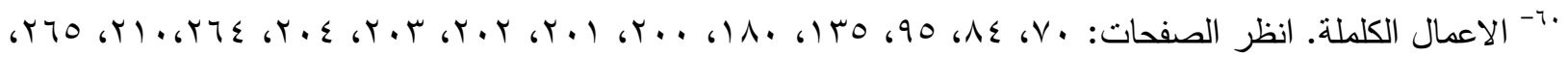

T. T T T

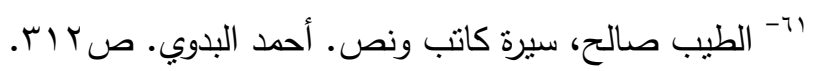

זٓ- تأملات في اسم الفاعل معناه وعمله من خلال القرآن الكريم وقراءاته. خالد بسندي. مجلة الألسن. جامعة عين شمس.

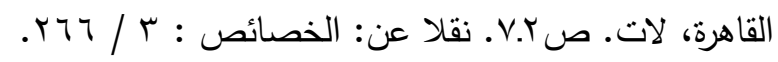

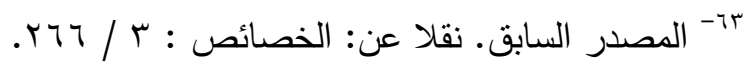

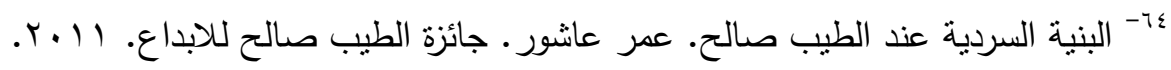

010- انظر: الاصالة والتجديد في تعريف الجملة وتصنيفها. سناء حميد البياتي. مركز إحياء التراث العلمي العربي. جامعة

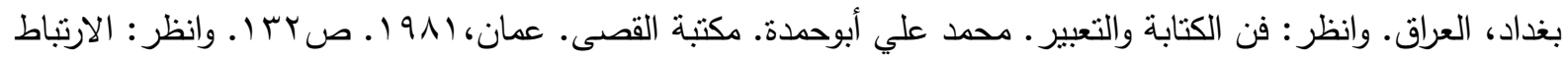
الربط في الجملة. مصدر سابق. وانظر : الجملة في النظام الغوي عند العرب. عبدالمجيد عيساني. جامعة قاصدي مرباح، ورقلة، الجزائر • موقع تخاطب.

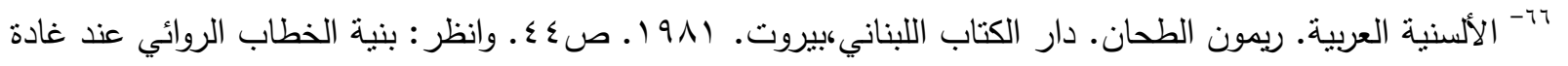
السمان. مصدر سابق. لآ- المثل السائر • ابن الاثير • تحق: محمد محي الدين عبدالمجيد. المكتبة المصرية،بيروت. 99 19 ـ وانظر : الانترنيت:

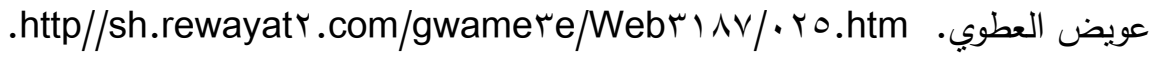
هף- علم المعاني. عبدالعزيز عتيق. وانظر : فن التحرير العربي. محمد صالح الثنطي. دار الاندلس للنشر والتوزيع.

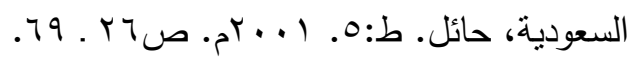

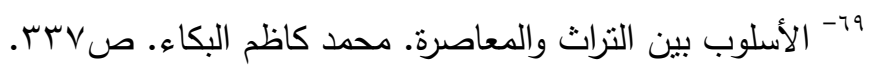

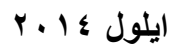




\section{مجية كيلة |تربية لمجامعة و اسط}

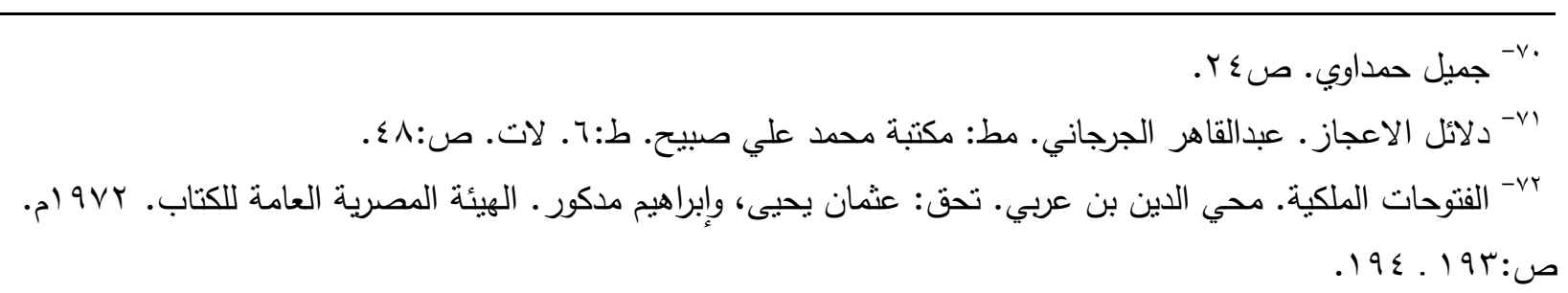

ايلول \& 1 ب r 